\title{
Synthesis and structural characterization of $N$-acetoacetylhydrazones and 2,5,5-trisubstituted 4-acetyl-3-pyrazolidinones
}

\author{
Kirill N. Zelenin, ${ }^{a}$ Sergei V. Oleinik, ${ }^{b}$ Anatolii A. Potekhin, ${ }^{b}$ Vladimir V. Ovcharenko, \\ Jari Sinkkonen, ${ }^{\mathrm{C}}$ Kalevi Pihlaja ${ }^{\mathrm{c}, *}$ \\ ${ }^{a}$ Russian Military Medical Academy, 194044 Saint-Petersburg, Russia, \\ ${ }^{b}$ Department of Chemistry, Saint-Petersburg State University, 198904 Saint-Petersburg, \\ Russia, and ${ }^{c}$ Department of Chemistry, University of Turku, Turku, FIN-20014, Finland \\ * Corresponding author: Tel. +(358-2)-333-6750; \\ E-mail:kpihlaja@utu.fi
}

\section{Dedicated to Prof. Gábor Bernáth on the occasion of his $\mathbf{7 0}^{\text {th }}$ birthday \\ (received 09 Jan 03; accepted 28 Apr 03; published on the web 02 May 03)}

\begin{abstract}
Reaction of diketene with N-substituted hydrazones of aldehydes and sterically crowded ketones leads to the corresponding $\mathrm{N}$-acetoacetylhydrazones. With hydrazones of other ketones, this reaction yields cyclic isomers of $\mathrm{N}$-acetoacetylhydrazones, namely, 2,5,5trisubstituted 4-acetylpyrazolidin-3-ones. The products where characterized by ${ }^{1} \mathrm{H}$ and ${ }^{13} \mathrm{C}$ NMR and electron ionization (EI) mass spectrometry. The EI mass spectra of the latter compounds and those of linear $\mathrm{N}$-acetoacetylhydrazones show that in the gas phase their molecular ions attain predominantly similar forms as the respective neutral compounds in solutions. The mass-spectrometric fragmentation of both forms is characterized by retrosynthetic cleavages with the loss of neutral acetylketene. The imines produced from 2,5,5trisubstituted 4-acetyl-3-pyrazoli-dinones and primary amines predominantly exist in solutions in the enamine form. The EI mass spectra of these condensation products show that in the gas phase their molecular ions exist as pyrazolidinones. Characteristic fragmentation paths under the EI conditions include the pyrazolidine ring cleavages at the N1-C5 and C3-C4 bonds, with the positive charge mainly localized in the enamine moiety. There is no evidence for ring-chain isomerism of the compounds studied.
\end{abstract}

Keywords: Diketene, alkylidenehydrazides, N-acetoacetylhydrazones, 4-acetylpyrazolidin-3ones, NMR, mass spectrometry

\section{Introduction}


Diketene is a useful synthon for heterocyclic chemistry. Its reactions with bifunctional nucleophiles, such as hydrazine derivatives, provide a method for the construction of the pyrazole ring. ${ }^{1}$ Among the reactions of this type, diketene interaction with hydrazones is of particular interest, but it has previously been carried out only with phenylhydrazones. ${ }^{2}$ Thus, phenylhydrazones of aldehydes were reported ${ }^{2}$ to produce $\mathrm{N}$-phenyl-N-acetoacetylhydrazones, whereas phenyl-hydrazones of ketones produced 5,5-disubstituted 4-acetyl-2phenylpyrazolidin-3-ones. It was found later $^{3}$ that both types of reaction products are capable of prototropic transformations and configurational isomerism in solution. Furthermore, the activated carbonyl group of these heterocyclic products has previously been subjected to hydrogenation and acetylation reactions, ${ }^{1}$ but not to the attack of nitrogen nucleophiles. To fill up this gap, we allowed a typical compound, 2,5-diphenyl-5-methyl-4-acetylpyrazolidin-3-one, to react with amines and hydrazines. In the present paper, the scope and synthetic utility of diketene reactions with hydrazones are systematically investigated, and product structures determined by spectroscopic methods.

\section{Results and Discussion}

\section{NMR}

It was found that diketene $\mathbf{1}$ reacts with unsubstituted hydrazones of ketones $\mathbf{2 a}$ or $\mathbf{2} \mathbf{b}$ in a 1:2 ratio to form the corresponding 3-(alkylidenehydrazono)butyric acid alkylidenehydrazides 3a or $\mathbf{3 b}$, respectively (Scheme 1 and Table 1). Formation of 1:1 adducts could not be achieved by varying the experimental conditions (such as the mixing order and ratios of the reagents, solvents, and temperatures). This reaction course is typical of 1-substituted and 1,1disubstituted hydrazine derivatives ${ }^{1}$ including semicarbazide. ${ }^{4}$ The NMR spectra of compounds $\mathbf{3}$ exhibit complex sets of signals corresponding to two azine forms, $\mathbf{A}$ and $\mathbf{A}^{\prime}$. Their existence is most probably due to geometrical isomerism with respect to one of the $\mathrm{C}=\mathrm{N}$ bonds and to interconversion with two tautomeric forms, $\mathbf{B}$ and $\mathbf{B}^{\prime}$, one of which is stabilized by an intramolecular hydrogen bond (IMHB). Each of these forms can exist as four $E / Z$ isomers at the $\mathrm{C}=\mathrm{N}$ bonds in the ketone residue, which accounts for the complexity of the spectra. The signals were assigned using previously established criteria. ${ }^{5}$ Thus, the $E$-isomer was found to dominate over the $Z$-isomer in hydrazidoazines $\mathbf{3}$ because the methyl groups signals for the $E$-isomer should be shifted upfield as compared to those of the $Z$-isomer, whereas the signals of the methylene groups should be downfield. In the enamine forms $\mathbf{B}$ and $\mathbf{B}^{\prime}$, the chemical shifts of the enamine NH signals are vastly different because the one which takes part in IMHB is shifted to $\approx 12 \mathrm{ppm}$. Signals in the downfield spectral range were assigned based on the correspondence between the intensities of the NH group signals and those of the other groups.

Table 1. ${ }^{1} \mathrm{H}$ NMR chemical shifts in ppm for hydrazidoazines $\mathbf{3 a}$ and $\mathbf{3 b}$ in $\mathrm{CDCl}_{3}$

\begin{tabular}{lllllllll} 
Compd. Form(s) $\%$ & $2 \mathrm{R}$ & $\mathrm{CH}_{3}$ & $\mathrm{CH}_{2}$ & $\mathrm{CH}=$ & $\mathrm{NHC}(\mathrm{O})$ & $\mathrm{NHC}=\mathrm{C}$ & $\begin{array}{l}\mathrm{NHC}=\mathrm{C} \\
(\mathrm{IMHB})\end{array}$ \\
\hline
\end{tabular}




\begin{tabular}{|c|c|c|c|c|c|c|c|c|c|}
\hline \multirow[t]{4}{*}{ 3a } & $\mathbf{A}$ and $\mathbf{A}^{\prime}$ & 28 & & & 3.22 br.s & & 10.35 br.s & & \\
\hline & & 12 & \multirow{3}{*}{\multicolumn{2}{|c|}{$2.13-2.67 \mathrm{~m}$}} & 3.14 br.s & - & 9.86 br.s & - & - \\
\hline & \multirow{2}{*}{$\mathbf{B}$ and $\mathbf{B}^{\prime}$} & 36 & & & - & 6.07 br.s & not detd. & not detd. & not detd. \\
\hline & & 24 & & & - & 6.16 br.s & not detd. & not detd. & not detd. \\
\hline \multirow[t]{3}{*}{$3 b$} & $\mathbf{A}$ or $\mathbf{A}^{\prime}$ & 35 & & & $\begin{array}{l}2.95- \\
3.15 \mathrm{~m}\end{array}$ & - & $10.38 \mathrm{~m}$ & - & - \\
\hline & $\mathbf{B}$ and $\mathbf{B}^{\prime}$ & 46 & $\begin{array}{c}7.2- \\
8.1 \mathrm{~m}\end{array}$ & $\begin{array}{c}2.05- \\
2.48 \mathrm{~m}\end{array}$ & - & $\begin{array}{l}5.77- \\
6.02 \mathrm{~m}\end{array}$ & $\begin{array}{c}9.1-9.2 \\
\mathrm{~m}\end{array}$ & $\begin{array}{c}12.56 \\
\text { br.s }\end{array}$ & - \\
\hline & & 19 & & & - & & & $\begin{array}{c}12.12 \\
\text { br.s }\end{array}$ & 17.92 br.s \\
\hline
\end{tabular}

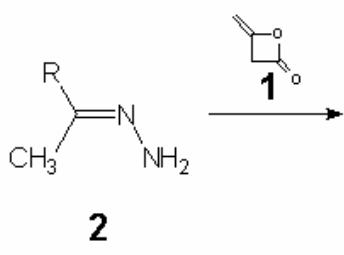<smiles>[R]C([R4])=NN=C(C)CC(=O)NN=C([R])[Y4]</smiles>

A<smiles>[R]C([R4])=N/N=C(/C)CC(=O)NN=C([R])[R]</smiles>

$A^{\prime}$<smiles>C=C</smiles>

3<smiles>[R]C([R4])=NNC(=O)C=C(C)NN=C([R])[R4]</smiles>

B

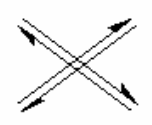<smiles>[R]C([R4])=NNC1=CC(C)N(N=C([R])[R4])[IH]O1</smiles>

B'

2, 3 a $R=M e, b$ R=Ph

\section{Scheme 1}

With N-alkyl- and N-arylhydrazones 2c-u, the 1:1 condensation products were readily obtained in satisfactory yields (Scheme 2) in all cases except methylhydrazones of acetaldehyde and acetone. Diketene reacted with these two hydrazones to form complex mixtures, from which individual components could not be isolated or identified. 
<smiles>[R]C([R])=NN([R])C(=O)CC(C)=O</smiles><smiles>[R1][C@@H]1NN([R])C(=O)[C@H]1C(C)=O</smiles>

c<smiles>[R7]C1NN([R])C(=O)[C@@H]1C(C)=O</smiles>

C'

A<smiles>C=C</smiles>

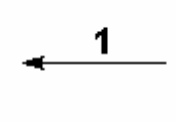<smiles></smiles>

B

4

\begin{tabular}{ccccc} 
& & $\mathrm{R}^{1}$ & $\mathrm{R}^{2}$ & $\mathrm{R}^{3}$ \\
\hline $\mathbf{2 , 4}$ & $\mathbf{c}$ & $\mathrm{H}$ & $\mathrm{Et}$ & $\mathrm{Me}$ \\
& $\mathbf{d}$ & $\mathrm{H}$ & $\mathrm{Ph}$ & $\mathrm{Me}$ \\
& $\mathbf{e}$ & $\mathrm{H}$ & $i \mathrm{Pr}$ & $\mathrm{Bn}$ \\
$\mathbf{f}$ & $\mathrm{H}$ & $\mathrm{Ph}$ & $\mathrm{Bn}$ \\
& $\mathbf{g}$ & $\mathrm{H}$ & $p-\mathrm{MeO}-\mathrm{C}_{6} \mathrm{H}_{4}$ & $\mathrm{Bn}$ \\
$\mathbf{h}$ & $\mathrm{H}$ & $p-\mathrm{NO}_{2}-\mathrm{C}_{6} \mathrm{H}_{4}$ & $\mathrm{Bn}$ \\
$\mathbf{i}$ & $\mathrm{H}$ & $p-\mathrm{MeO}-\mathrm{C}_{6} \mathrm{H}_{4}$ & $\mathrm{Ph}$ \\
$\mathbf{j}$ & $\mathrm{Me}$ & $t-\mathrm{Bu}$ & $\mathrm{Me}$ \\
$\mathbf{k}$ & $\mathrm{Me}$ & $t-\mathrm{Bu}$ & $\mathrm{Bn}$ \\
$\mathbf{l}$ & $\mathrm{Ph}$ & $\mathrm{Ph}$ & $\mathrm{Bn}$
\end{tabular}

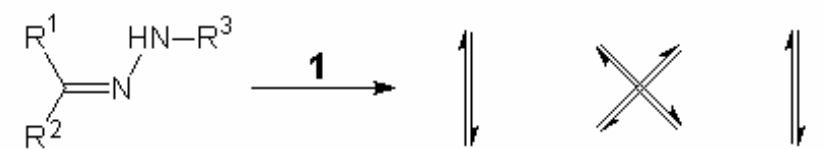

2<smiles>[R]N1NC([R1])([R])C2=C(C)O[CH][O+]=C21</smiles>

D<smiles>[R]N1NC([R1])([R])C(=C(C)O)C1=O</smiles>

D'

\section{5}

\begin{tabular}{cccc} 
& \multicolumn{3}{c}{$\mathrm{R}^{1}=\mathrm{Me}$} \\
\hline $\mathbf{2 , 5 :}$ & $\mathrm{R}^{2}$ & $\mathrm{R}^{3}$ \\
& $\mathbf{m}$ & $\mathrm{Ph}$ & $\mathrm{Me}$ \\
$\mathbf{n}$ & $\mathrm{Me}$ & $i \mathrm{Pr}$ \\
$\mathbf{0}$ & $\mathrm{Ph}$ & $i \mathrm{Pr}$ \\
$\mathbf{p}$ & $\mathrm{Me}$ & $\mathrm{Bn}$ \\
$\mathbf{q}$ & $\mathrm{Me}$ & $\mathrm{Ph}$ \\
$\mathbf{r}$ & $\mathrm{Et}$ & $\mathrm{Ph}$ \\
$\mathbf{s}$ & $\mathrm{Ph}$ & $\mathrm{Ph}$ \\
$\mathbf{t}$ & $p-\mathrm{NO}_{2} \mathrm{C}_{6} \mathrm{H}_{4}$ & $\mathrm{Ph}$ \\
$\mathbf{u}$ & $\mathrm{Ph}$ & $p-\mathrm{NO}_{2} \mathrm{C}_{6} \mathrm{H}_{4}$
\end{tabular}

\section{Scheme 2}

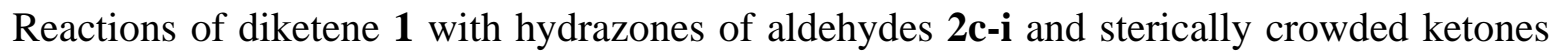
(pinacolone and benzophenone) $\mathbf{2 j - 1}$ gave the corresponding N-substituted $\mathrm{N}$ acetoacetylhydrazones $\mathbf{4} \mathbf{c}-\mathbf{i}$ and $\mathbf{4 j - l}$, respectively. According to the ${ }^{1} \mathrm{H}$ and ${ }^{13} \mathrm{C}$ NMR spectra (Tables 2 and S1-S3, see Supporting Information section), the structural features of these compounds are characteristic of acetoacetic acid amides. ${ }^{6}$ There are two sets of signals in the spectra of 4 in DMSO- $d_{6}$ and $\mathrm{CDCl}_{3}$. One of these sets includes a proton signal from a hydrogen-bonded enolic hydroxyl group (form B). The aldehyde derivatives were found to contain up to $11 \%$ of the enol form $\mathbf{B}$. The fraction of this form increases to $30 \%$ for the ketone derivatives.

Table 2. ${ }^{1} \mathrm{H}$ NMR chemical shifts (in ppm) and coupling constants (Hz, in parentheses) of Nacetoacetylhydrazones 4 in $\mathrm{CDCl}_{3}$. ${ }^{13} \mathrm{C}$ NMR results in $\mathrm{CDCl}_{3}$ and ${ }^{1} \mathrm{H} \mathrm{NMR}$ and ${ }^{13} \mathrm{C} \mathrm{NMR}$ 
results in DMSO- $d_{6}$ are presented in the Supporting Information section (Tables S1-S3, respectively)

\begin{tabular}{|c|c|c|c|c|c|c|c|c|c|c|}
\hline Compd. & Form & $\%$ & $\mathrm{R}^{1}$ & $\mathrm{R}^{2}$ & $\mathrm{R}^{3}$ & $\begin{array}{c}\mathrm{CH}_{3} \mathrm{CO}, \\
\mathrm{s}\end{array}$ & $\mathrm{C}_{\underline{3}} \mathrm{C}(\mathrm{OH})$ & $\mathrm{CH}_{2}, \mathrm{~s}$ & $\mathrm{CH}=\mathrm{C}$ & OH, br.s \\
\hline 4c & A & 100 & $\begin{array}{l}6.86 \mathrm{t} \\
(4.5)\end{array}$ & $\begin{array}{c}0.82 \mathrm{t}(7.4) \\
2.06 \mathrm{dq}(4.5, \\
7.4)\end{array}$ & $2.93 \mathrm{~s}$ & 1.95 & - & 3.53 & - & - \\
\hline \multirow[t]{2}{*}{$4 d$} & A & 94 & 7.27 & 7.3-7.6 & $3.27 \mathrm{~s}$ & 2.19 & - & 3.86 & - & - \\
\hline & B & 6 & & & $3.24 \mathrm{~s}$ & - & 1.96 & - & 6.15 & 13.79 \\
\hline \multirow[t]{2}{*}{$4 e$} & A & 95 & $\begin{array}{l}6.82 \mathrm{~d} \\
(4.5)\end{array}$ & $\begin{array}{c}0.86 \mathrm{~d}(6.6) \\
2.28 \mathrm{~m}\end{array}$ & $\begin{array}{c}5.03 \mathrm{~s} \\
7.0-7.3 \mathrm{~m}\end{array}$ & 2.17 & - & 3.65 & - & - \\
\hline & B & 5 & $\begin{array}{l}6.87 \mathrm{~d} \\
(4.6)\end{array}$ & $\begin{array}{c}0.92 \mathrm{~d}(6.8) \\
2.28 \mathrm{~m}\end{array}$ & $\begin{array}{c}5.18 \mathrm{~s} \\
7.0-7.3 \mathrm{~m}\end{array}$ & - & 1.94 & 3.98 & 6.12 & 13.90 \\
\hline \multirow[t]{2}{*}{$4 f$} & A & 94 & 7.65 & $7.2-7.6 \mathrm{~m}$ & $\begin{array}{c}5.30 \mathrm{~s} \\
7.2-7.6 \mathrm{~m}\end{array}$ & 2.36 & - & 4.10 & - & - \\
\hline & B & 6 & 7.68 & & & - & 2.13 & - & 6.37 & 13.87 \\
\hline \multirow[t]{2}{*}{$4 g$} & A & 94 & 7.60 & $\begin{array}{c}3.78 \mathrm{~s} \\
\left(\mathrm{CH}_{3} \mathrm{O}\right) \\
6.8-7.5 \mathrm{~m}\end{array}$ & $\begin{array}{c}5.26 \mathrm{~s} \\
6.8-7.5 \mathrm{~m}\end{array}$ & 2.33 & - & 4.05 & - & - \\
\hline & B & 6 & 7.63 & & & - & 2.10 & - & 6.34 & 13.91 \\
\hline \multirow[t]{2}{*}{$4 h$} & A & 90 & 7.30 & $7.1-8.3 \mathrm{~m}$ & $\begin{array}{c}5.30 \mathrm{~s}, \\
7.1-8.3 \mathrm{~m}\end{array}$ & 2.35 & - & 4.12 & - & - \\
\hline & B & 10 & $\begin{array}{l}\text { not } \\
\text { detd. }\end{array}$ & & & - & 2.14 & - & 6.29 & 13.68 \\
\hline \multirow[t]{2}{*}{$4 i$} & A & 89 & $\begin{array}{c}6.24 \text { br. } \\
\text { s }\end{array}$ & $\begin{array}{r}6.8-7.6 \mathrm{~m}(A \\
(\mathrm{Me}\end{array}$ & $\begin{array}{l}\text { Ar), } 3.78 \mathrm{~s} \\
\text { O) }\end{array}$ & 2.35 & - & 4.07 & - & - \\
\hline & B & 11 & $\begin{array}{c}6.59 \text { br. } \\
\text { s }\end{array}$ & & & - & 2.08 & - & 6.59 & 13.84 \\
\hline \multirow[t]{2}{*}{$4 j$} & A & 96 & 1.73 & 0.97 & 1.84 & 2.00 & - & 2.91 & - & - \\
\hline & B & 4 & 1.65 & 1.03 & 1.83 & - & 2.08 & - & 6.00 & 13.96 \\
\hline \multirow[t]{2}{*}{$4 k$} & A & 70 & 1.01 & 1.58 & $\begin{array}{c}4.71 \mathrm{~s} \\
7.1-7.3 \mathrm{~m}\end{array}$ & 2.09 & - & 3.30 & - & - \\
\hline & B & 30 & 1.07 & 1.55 & $\begin{array}{c}4.60 \mathrm{~s}, \\
7.1-7.3 \mathrm{~m}\end{array}$ & - & 1.94 & - & 6.22 & 14.39 \\
\hline \multirow[t]{2}{*}{41} & A & 90 & $\begin{array}{c}6.9-7.5 \\
\mathrm{~m}\end{array}$ & $6.9-7.5 \mathrm{~m}$ & $\begin{array}{c}4.59 \mathrm{~s}, \\
6.9-7.5 \mathrm{~m}\end{array}$ & 2.18 & - & 3.97 & - & - \\
\hline & B & 10 & & & & - & 2.00 & - & 5.75 & 14.26 \\
\hline
\end{tabular}

The interaction of diketene $\mathbf{1}$ with $\mathrm{N}$-alkyl- and N-arylhydrazones of less-crowded ketones gives the corresponding 2,5,5-trisubstituted 4-acetylpyrazolidine-3-ones 5m-u (Scheme 2). According to their ${ }^{1} \mathrm{H}$ and ${ }^{13} \mathrm{C}$ NMR spectra (Tables 3, 4 and S4, S5, respectively), these compounds contain a set of four cyclic tautomers including two diastereoisomers $\mathbf{C}$ and $\mathbf{C}^{\prime}$ and 
two enol forms $\mathbf{D}$ and $\mathbf{D}^{\prime}$. The form $\mathbf{C}$ dominates and form $\mathbf{D}^{\prime}$ is only manifested in polar solvents, evidently as a result of stabilization due to solvation effects. For compounds $\mathbf{5 s}$ and $\mathbf{5 t}$ in DMSO- $d_{6}$, $\mathbf{D}^{\prime}$ prevails over $\mathbf{D}$ due to the solvent's ability to form intermolecular hydrogen bonds that destabilizes the formation of $\mathbf{D}$.

Table 3. ${ }^{1} \mathrm{H}$ NMR chemical shifts in ppm and coupling constants in $\mathrm{Hz}$ (in parentheses) of 2,5,5-trisubstituted 4-acetyl-3-pyrazolidinones 5 in $\mathrm{CDCl}_{3} \cdot{ }^{13} \mathrm{C} \mathrm{NMR}$ results in $\mathrm{CDCl}_{3}$ are presented in the Supporting Information section (Table S4)

\begin{tabular}{|c|c|c|c|c|c|c|c|c|c|c|}
\hline Compd & Form & $\%$ & $\mathrm{R}^{1}$ & $\mathrm{R}^{2}$ & $\mathrm{R}^{3}$ & $\begin{array}{c}\mathrm{CH}_{3} \mathrm{CO} \\
\mathrm{s}\end{array}$ & $\begin{array}{c}\mathrm{CH}_{3} \mathrm{C}(\mathrm{OH}), \\
\mathrm{s}\end{array}$ & $\begin{array}{c}\mathrm{CH}_{2}, \\
\mathrm{~s}\end{array}$ & $\begin{array}{c}\mathrm{CH}=\mathrm{C}, \\
\mathrm{s}\end{array}$ & $\begin{array}{l}\mathrm{OH}, \\
\text { br.s }\end{array}$ \\
\hline \multirow[t]{2}{*}{$4 c$} & A & 97 & $\begin{array}{l}7.21 \mathrm{t} \\
(4.5)\end{array}$ & $\begin{array}{c}1.03 \mathrm{t} \\
(7.4), 2.27 \\
\mathrm{dq} \\
(4.5,7.4)\end{array}$ & 3.12 & 2.16 & - & 3.74 & - & - \\
\hline & B & 3 & $\begin{array}{l}7.29 \mathrm{t} \\
(4.7)\end{array}$ & $\begin{array}{c}1.08 \mathrm{t} \\
(7.5), 2.31 \\
\mathrm{dq} \\
(4.7,7.5)\end{array}$ & 3.16 & - & 1.94 & - & 6.01 & 14.00 \\
\hline \multirow[t]{2}{*}{ 4d } & A & 96 & 7.35 & 7.4-7.8 m & 3.32 & 2.22 & - & 3.96 & - & - \\
\hline & B & 4 & 7.36 & & 3.33 & - & 2.08 & - & 6.27 & 14.00 \\
\hline \multirow[t]{2}{*}{$4 e$} & A & 94 & $\begin{array}{c}7.02 \mathrm{~d} \\
(4.4)\end{array}$ & $\begin{array}{c}0.91 \mathrm{~d} \\
(6.7)\end{array}$ & $\begin{array}{c}5.11 \mathrm{~s}, 7.2- \\
\quad 7.4 \mathrm{~m}\end{array}$ & 2.21 & - & 3.91 & - & - \\
\hline & B & 6 & $\begin{array}{c}7.15 \mathrm{~d} \\
(4.4)\end{array}$ & $\begin{array}{c}0.96 \mathrm{~d} \\
(6.8)\end{array}$ & $\begin{array}{c}5.16 \mathrm{~s}, 7.2- \\
\quad 7.4 \mathrm{~m}\end{array}$ & - & 1.99 & - & 6.14 & 14.03 \\
\hline \multirow[t]{2}{*}{$4 g$} & A & 96 & 7.77 & $\begin{array}{c}3.76 \mathrm{~s} \\
\text { (OMe), } \\
6.9-7.6 \mathrm{~m}\end{array}$ & $\begin{array}{c}5.26 \mathrm{~s}, 6.9- \\
\quad 7.6 \mathrm{~m}\end{array}$ & 2.28 & - & 4.07 & - & - \\
\hline & B & 4 & 7.82 & & $\begin{array}{c}5.30 \mathrm{~s}, 6.9- \\
\quad 7.6 \mathrm{~m}\end{array}$ & - & 2.07 & - & 6.35 & 14.00 \\
\hline \multirow[t]{2}{*}{$4 h$} & A & 90 & 7.33 & 7.1-8.3 m & $\begin{array}{c}5.29 \mathrm{~s}, 7.1- \\
\quad 8.3 \mathrm{~m}\end{array}$ & 2.30 & - & 4.16 & - & - \\
\hline & B & 10 & $\begin{array}{l}\text { not } \\
\text { detd. }\end{array}$ & & & - & 2.08 & - & 6.38 & 13.05 \\
\hline \multirow[t]{2}{*}{$4 i$} & A & 90 & 7.01 & $\begin{array}{c}7.2-7.7 \mathrm{~m} \\
(\mathrm{Ar}), 3.78 \\
\mathrm{~s}(\mathrm{OMe})\end{array}$ & 7.2-7.7 m & 2.29 & - & 4.11 & - & - \\
\hline & B & 10 & 6.92 & & & - & 2.07 & - & 6.42 & 13.21 \\
\hline \multirow[t]{2}{*}{$4 j$} & A & 95 & 1.86 & 1.10 & 1.90 & 2.08 & - & 2.95 & - & - \\
\hline & B & 5 & 1.84 & 1.06 & Not detd. & - & 2.02 & - & 6.24 & 14.48 \\
\hline 41 & A & 93 & $\begin{array}{c}6.9- \\
7.6 \mathrm{~m}\end{array}$ & 6.9-7.6 m & $\begin{array}{c}4.45 \mathrm{~s}, 6.9- \\
7.6 \mathrm{~m}\end{array}$ & 2.11 & - & 3.96 & - & - \\
\hline
\end{tabular}




\section{B 7}

1.92

$5.63 \quad 14.32$

Table 4. ${ }^{13} \mathrm{C}$ NMR chemical shifts (in ppm) of 2,5,5-trisubstituted 4-acetyl-3-pyrazolidinones 5 in DMSO- $d_{6} \cdot{ }^{13} \mathrm{C}$ NMR results in DMSO- $d_{6}$ are presented in the Supporting Information section (Table S5)

\begin{tabular}{|c|c|c|c|c|c|c|c|c|c|c|c|}
\hline Compd. & Form & $\mathrm{R}^{1}$ & $\mathrm{R}^{2}$ & $\mathrm{R}^{3}$ & $\mathrm{CH}_{3}$ & $\mathrm{CH}_{2}$ & $\underline{\mathrm{CH}}=\mathrm{C}$ & $\mathrm{C}=\mathrm{N}$ & $\mathrm{CH}_{3} \mathrm{C}(\mathrm{OH})$ & $\begin{array}{c}\mathrm{N}- \\
\mathrm{C}(\mathrm{O})\end{array}$ & $\mathrm{CH}_{3} \mathrm{CO}$ \\
\hline $4 c$ & A & - & $10.8,26.2$ & 30.2 & 27.3 & 50.1 & - & 144.8 & - & 168.7 & 202.2 \\
\hline \multirow[t]{3}{*}{ 4d } & A & - & $126-136$ & 30.3 & 28.0 & 50.7 & - & 140.7 & - & 169.3 & 202.3 \\
\hline & B & - & & 27.4 & 22.4 & - & 87.3 & 139.9 & 192.7 & 172.7 & - \\
\hline & & & & $44.3,126-$ & & & & & & & \\
\hline \multirow[t]{4}{*}{$4 e$} & A & - & 19.9, 30.5 & 135 & 32.0 & 50.8 & - & 149.9 & - & 169.5 & 202.1 \\
\hline & & & & $43.8,126-$ & & & & & & & \\
\hline & B & - & $22.3,30.6$ & 135 & 22.2 & - & 88.7 & not detd. & 188.7 & 173.1 & - \\
\hline & & & & $45.1,126-$ & & & & & & & \\
\hline \multirow[t]{4}{*}{$4 f$} & A & - & $126-135$ & 135 & 30.5 & 51.0 & - & 141.6 & - & 169.8 & 202.1 \\
\hline & & & & $44.5,126-$ & & & & & & & \\
\hline & B & - & & 135 & 22.6 & - & 88.8 & not detd. & 194.0 & 176.2 & - \\
\hline & & & $55.7,126-$ & $45.0,126-$ & & & & & & & \\
\hline \multirow[t]{4}{*}{$4 g$} & A & - & 136 & 162 & 30.4 & 51.1 & - & 141.4 & - & 169.6 & 202.2 \\
\hline & & & & $44.5,126-$ & & & & & & & \\
\hline & B & - & & 162 & 22.5 & - & 88.9 & 140.7 & 189.5 & 173.2 & - \\
\hline & & & & $45.5,124-$ & & & & & & & \\
\hline \multirow[t]{4}{*}{$4 h$} & A & - & $124-141$ & 149 & 30.5 & 50.9 & - & 140.5 & - & 169.9 & 201.7 \\
\hline & & & & $44.8,121-$ & & & & & & & \\
\hline & B & - & & 149 & 22.6 & - & 88.5 & 141.0 & 186.0 & 177.2 & - \\
\hline & & & $55.0,113-$ & & & & & & & & \\
\hline \multirow[t]{2}{*}{$4 i$} & A & - & 168 & 113-161 & 29.6 & 50.6 & - & 142.2 & - & 168.5 & 201.5 \\
\hline & B & - & & & 21.8 & - & 88.4 & not detd. & 175.6 & 172.0 & - \\
\hline \multirow[t]{3}{*}{$4 j$} & A & 14.9 & 27.9 & 50.3 & 30.0 & 51.9 & - & 167.5 & - & 183.8 & 202.1 \\
\hline & B & 14.0 & & 50.1 & 21.0 & - & 87.1 & not detd. & 174.7 & 185.6 & - \\
\hline & & & & $50.8,127-$ & & & & & & & \\
\hline \multirow[t]{4}{*}{$4 k$} & A & 15.3 & 28.0 & 137 & 30.2 & 51.4 & - & 166.4 & - & 185.9 & 202.1 \\
\hline & & & & $50.5,127-$ & & & & & & & \\
\hline & B & 14.5 & & 137 & 22.3 & - & 87.8 & not detd. & 184.0 & 187.2 & - \\
\hline & & & & $49.0,127-$ & & & & & & & \\
\hline \multirow[t]{3}{*}{41} & A & \multirow{2}{*}{\multicolumn{2}{|c|}{$127-139$}} & 139 & 31.1 & 51.2 & - & 162.4 & - & 170.8 & 202.5 \\
\hline & & & & $49.2,127-$ & & & & & & & \\
\hline & B & & & 139 & 22.4 & - & 89.3 & not detd. & 190.9 & 175.7 & - \\
\hline
\end{tabular}


Stereoisomer $\mathbf{C}$ should be more abundant than $\mathbf{C}^{\prime}$ because of trans-arrangement of the bulky substituents in positions 4 and 5. Since the hydroxyl group of $\mathbf{D}$ participates in the hydrogen bond, its signal should resonate in a lower field. The integral intensities were analysed in order to assign the rest of the signals. Variation of the sample concentration (e.g. for 5s) in DMSO- $d_{6}$ solution did not affect the $\mathrm{OH}$ signal at $12.35 \mathrm{ppm}$, confirming its involvement in an IMHB. According to the NMR spectra, increasing the solution temperature to $50^{\circ} \mathrm{C}$ leads to a relative increase in the content of forms $\mathbf{C}^{\prime}$ and $\mathbf{D}$ over that of form $\mathbf{C}$. At the same time the fraction of $\mathbf{D}^{\prime}$ decreases, probably because the stabilizing solvation effect becomes weaker. It should be noted that the $\mathrm{NH}$ and $\mathrm{CH}_{3}$ signals of the form $\mathbf{C}$ in compound $\mathbf{5 s}$ $\left(\mathrm{R}^{2}=\mathrm{R}^{3}=\mathrm{Ph}\right)$ are resolved into two closely spaced singlets with approximately equal intensities. This phenomenon probably indicates a conformational ring rearrangement. The assignments for each of the "keto" forms $\mathbf{C}$ and $\mathbf{C}^{\prime}$ of 5 s are in agreement with the NOESY data. The quantitative information obtained from the nuclear Overhauser effect suggests that the minor set of signals in one of these forms $\left(\mathbf{C}^{\prime}\right)$ corresponds to the configuration with cisarrangement of the phenyl and acetyl groups, whereas the major set of signals corresponds to the trans-configuration. Information about exchange processes indicates that mutual transformations exist between forms $\mathbf{C}, \mathbf{C}^{\prime}$ and $\mathbf{D}^{\prime}$. No exchange of form $\mathbf{D}$ with the other forms was observed using 1 sec of mixing time. This indicates a sufficiently high barrier of isomerization from $\mathbf{C}$ and $\mathbf{C}^{\prime}$ to $\mathbf{D}$. Note also that it takes several days for the tautomeric equilibria to be established both in hydrazones $\mathbf{4}$ and in their cyclic isomers $\mathbf{5}$. At the moment of dissolving the sample, only one tautomeric form was present in each case, namely, A for hydrazones $\mathbf{4}$ and $\mathbf{C}$ (or $\mathbf{C}^{\prime}$ ) for the cyclic derivatives $\mathbf{5}$.

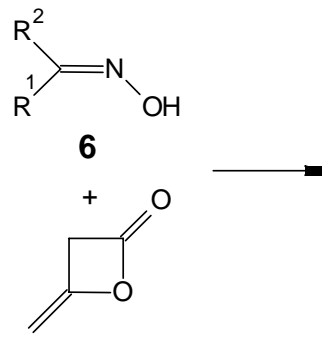

1

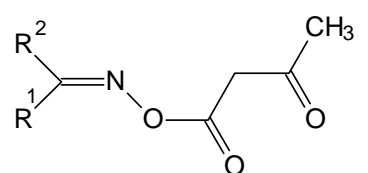

A

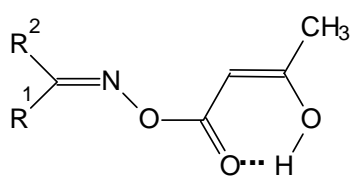

B

7

6, 7: (a) $\mathrm{R}^{1}=\mathrm{H}, \mathrm{R}^{2}=\mathrm{Me} ;$ (b) $\mathrm{R}^{1}=\mathrm{Me}, \mathrm{R}^{2}=\mathrm{Me} ;$ (c) $\mathrm{R}^{1}=\mathrm{Me}, \mathrm{R}^{2}=\mathrm{Ph}$.

\section{Scheme 3}

In order to expand the synthetic scope of the reaction studied, the action of diketene $\mathbf{1}$ on oximes 6a-c was subsequently studied. The reaction yielded trans-O-acetoacetyloximes 7a-c (Scheme 3, Tables 5 and S6). Compounds 7 exist in solutions in two forms, $\mathbf{A}$ and $\mathbf{B}$. In a less polar solvent, the fraction of the enolized form $\mathbf{B}$ increases. This behaviour is typical of 
acetoacetic esters. ${ }^{5}$ Since the starting oximes all exist as trans-isomers, additional signals in the NMR spectra of their derivatives $\mathbf{7}$ were assigned to the enol form $\mathbf{B}$ with an IMHB.

The reaction of 5,5-dimethyl-2-isopropyl-4-acetyl-pyrazolidin-3-one (5n) and 2,5-diphenyl5-methyl-4-acetyl-pyrazolidin-3-one (5s) with amines 8a-h (Scheme 4) produced the corresponding amine derivatives 9a-h in high yields (70-90\%). According to the ${ }^{1} \mathrm{H}$ NMR spectra (Tables 6 and S7), compounds $\mathbf{9}$ exist as enamine tautomers $\mathbf{B}$ stabilized by IMHB. This conclusion follows from the following data. There is only one set of signals in each of the ${ }^{1} \mathrm{H}$ NMR spectra, with the integral intensity corresponding to the number of protons in the molecule. The $\mathrm{H}_{(4)}$ signal in the range of 3.2-4.2 ppm is missing, but there is a signal within 9$11 \mathrm{ppm}$ assignable to the amine proton bound by the side-chain nitrogen atom. The NH-proton in $\mathbf{B}$ takes part in a hydrogen bond and therefore its signal is considerably shifted downfield. The NMR data on compounds $\mathbf{9}$ are in complete agreement with the modern concepts about the structure of imines of $\beta$-ketoamides to which group these compounds belong. ${ }^{2}$

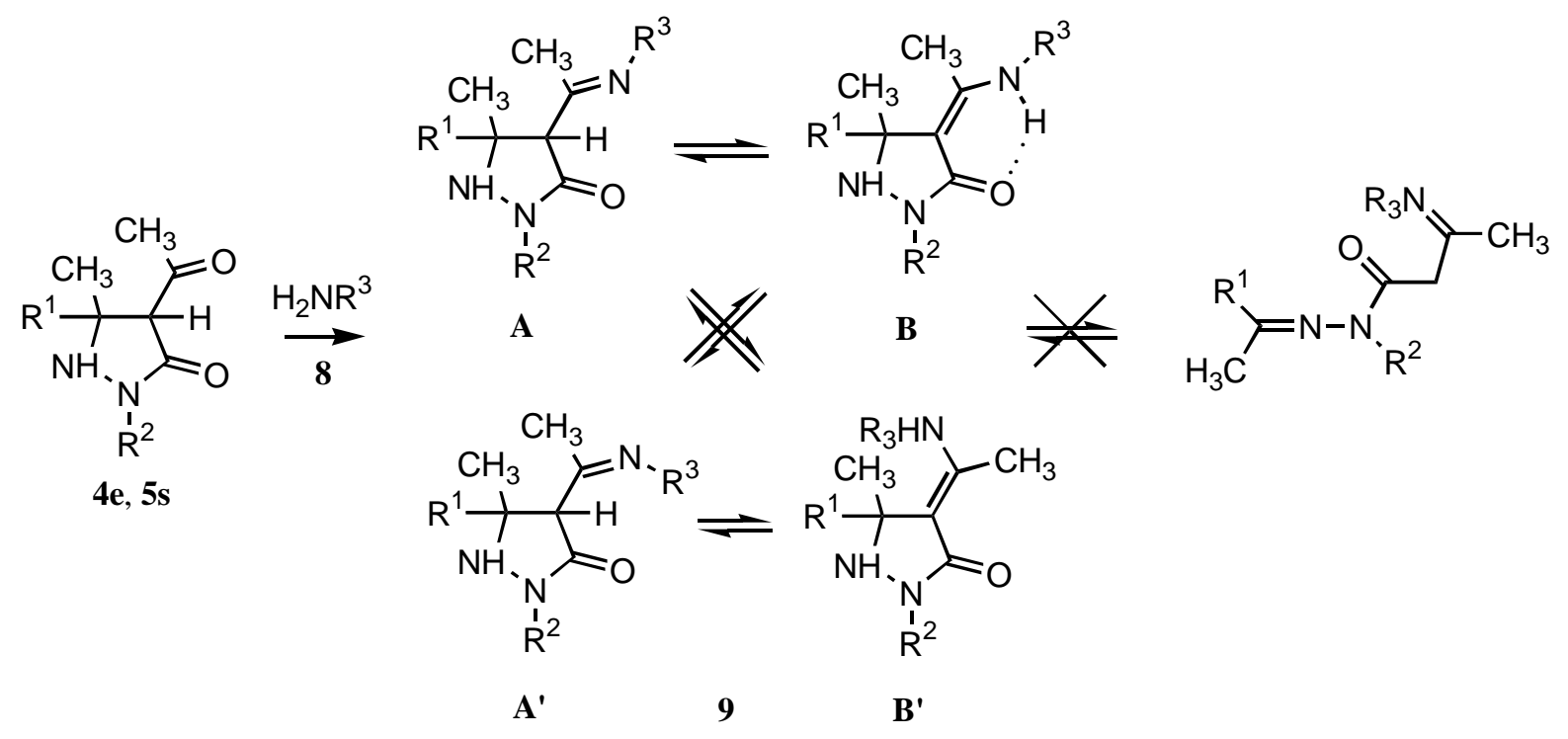

a: $\mathrm{R}^{1}=\mathrm{R}^{3}=\mathrm{Me}, \mathrm{R}^{2}=i-\mathrm{Pr}, \mathbf{b}-\mathbf{k}: \mathrm{R}^{1}=\mathrm{R}^{2}=\mathrm{Ph}, \mathbf{b}: \mathrm{R}^{3}=\mathrm{Me}, \mathbf{c}: \mathrm{R}^{3}=$ sec $-\mathrm{Bu}$, d: $\mathrm{R}^{3}=\mathrm{Bn}, \mathbf{e}: \mathrm{R}^{3}=$ allyl, f: $\mathrm{R}^{3}=\mathrm{Ph}, \mathbf{g}: \mathrm{R}^{3}=\mathrm{C}_{6} \mathrm{H}_{4} \mathrm{OMe}-4$

\section{Scheme 4}

In principle one cannot rule out the possibility of compounds $\mathbf{9}$ existing (if only partially) as linear hydrazones C. However, no indication of this form has been observed in solutions. In order to find out whether the open-chain isomers of $\mathbf{9}$ can possibly exist in the gas phase, their mass spectra were also investigated. 
Table 5. ${ }^{1} \mathrm{H}$ NMR chemical shifts in ppm and coupling constants in $\mathrm{Hz}$ (in parentheses) of Oacetoacetyloximes (7) in $\mathrm{CDCl}_{3} \cdot{ }^{1} \mathrm{H}$ NMR results in DMSO- $d_{6}$ are presented in the Supporting Information section (Table S6)

\begin{tabular}{ccccccccc}
\hline Compound & Forms & $\%$ & $\mathrm{R}^{1}$ & $\mathrm{R}^{2}$ & $\mathrm{CH}_{3} \mathrm{CO}, \mathrm{s}$ & $\mathrm{CH}_{2}, \mathrm{~s}$ & $\mathrm{CH}, \mathrm{s}$ & $\mathrm{OH}, \mathrm{s}$ \\
\hline 7a & $\mathbf{A}$ & 70 & $7.89, \mathrm{q}(6.2)$ & $2.05, \mathrm{~d}(6.2)$ & 2.32 & 3.68 & - & - \\
& $\mathbf{B}$ & 30 & $7.38, \mathrm{q}(6.6)$ & $2.13, \mathrm{~d}(6.6)$ & 2.22 & - & 5.37 & 11.92 \\
$7 \mathbf{b}$ & $\mathbf{A}$ & 85 & $1.97 \mathrm{~s}$ & $1.96 \mathrm{~s}$ & 2.25 & 3.70 & - & - \\
& $\mathbf{B}$ & 15 & $2.03 \mathrm{~s}$ & $1.94 \mathrm{~s}$ & 2.23 & - & 5.04 & 12.01 \\
$7 \mathbf{7}$ & $\mathbf{A}$ & 75 & $2.58 \mathrm{~s}$ & $7.49-8.10 \mathrm{~m}$ & 2.53 & 3.96 & - & - \\
& $\mathbf{B}$ & 25 & & & 2.35 & - & 5.85 & 12.09 \\
\hline
\end{tabular}

Table 6. ${ }^{1} \mathrm{H}$ NMR chemical shifts in ppm and coupling constants in $\mathrm{Hz}$ (in parentheses) of imines (9) of 2,5,5-trisubstituted 4-acetylpyrazolidin-3-ones in $\mathrm{CDCl}_{3}$. ${ }^{1} \mathrm{H}$ NMR results in DMSO- $d_{6}$ are presented in the Supporting Information section (Table S7)

\begin{tabular}{|c|c|c|c|c|c|c|c|c|}
\hline Compd. & Form & $\%$ & $\begin{array}{c}\mathrm{CH}_{3}, \\
\mathrm{~s}\end{array}$ & $\mathrm{R}^{2}$ & $\mathrm{R}^{3}$ & $\begin{array}{c}\mathrm{CH}_{3} \mathrm{C}\left(\mathrm{sp}^{2}\right) \\
\mathrm{s}\end{array}$ & $\begin{array}{c}\mathrm{NH}_{(1)}, \\
\mathrm{s}\end{array}$ & $\mathrm{NH}-\mathrm{R}^{3}$ \\
\hline 9a & B & 100 & $\begin{array}{l}1.10 \mathrm{~s}, \\
1.14 \mathrm{~s}\end{array}$ & $\begin{array}{c}1.02 \mathrm{~d} \\
(6.5), \\
4.12 \mathrm{sept} \\
\quad(6.5)\end{array}$ & $2.98 \mathrm{~d}(6.2)$ & 1.82 & 4.39 & $9.10 \mathrm{~m}$ \\
\hline $9 \mathbf{b}$ & B & 100 & 1.59 & 6.7-7.9 m & $2.90 \mathrm{~d}(5.1)$ & 1.80 & 4.39 & $9.07 \mathrm{~m}$ \\
\hline 9c & B & 100 & 1.59 & 6.9-7.9 m & $\begin{array}{c}0.97 \mathrm{t}(7.4), 1.21 \mathrm{~d} \\
(6.4), 1.55 \mathrm{~m}, 3.44 \\
\mathrm{~d} \cdot \operatorname{sext}(6.4,9.1)\end{array}$ & 1.80 & 4.36 & $\begin{array}{c}9.06 \mathrm{~d} \\
(9.1)\end{array}$ \\
\hline 9d & B & 100 & 1.61 & $7.0-8.0 \mathrm{~m}$ & $\begin{array}{c}4.46 \mathrm{~d}(6.3), 7.0-8.0 \mathrm{~m} \\
3.84 \mathrm{~m}\left[\mathrm{C}\left(\mathrm{sp}^{3}\right) \mathrm{H}_{2}\right], 5.16\end{array}$ & 1.84 & 4.44 & $9.60 \mathrm{~m}$ \\
\hline $9 e$ & B & 100 & 1.58 & $7.0-7.9 \mathrm{~m}$ & $\begin{array}{c}\mathrm{m}(\mathrm{CH}) \\
5.35 \text { and } 5.92 \mathrm{~m} \\
{\left[\mathrm{C}\left(\mathrm{sp}^{2}\right) \mathrm{H}_{2}\right]}\end{array}$ & 1.81 & 4.40 & $9.24 \mathrm{~m}$ \\
\hline 9f & B & 100 & 1.66 & $7.0-7.9 \mathrm{~m}$ & $7.0-7.9 \mathrm{~m}$ & 1.84 & 4.47 & $10.99 \mathrm{~s}$ \\
\hline $9 g$ & B & 100 & 1.56 & $6.8-8.0 \mathrm{~m}$ & $3.80 \mathrm{~s}(\mathrm{MeO}), 6.8-8.0 \mathrm{~m}$ & 1.84 & 4.36 & $10.80 \mathrm{~s}$ \\
\hline $9 h$ & B & 100 & 1.84 & $7.0-8.2 \mathrm{~m}$ & $7.0-8.2 \mathrm{~m}$ & 1.87 & 4.54 & $11.58 \mathrm{~s}$ \\
\hline
\end{tabular}

\section{Mass spectrometry}

The mass spectrometry of 4-acetylpyrazolidine-3-ones has not yet been systematically studied. An earlier report ${ }^{7}$ concluded that the molecular ions of 4-(thio)benzoyl-1-phenylpyrazole-5-one predominantly exist in the hydroxy form (Scheme 5). A similar structure was assigned to $\mathrm{M}^{+\bullet}$ of the 4-acetyl derivative (Scheme 5). The electron impact-induced fragmentation of this compound included heterocycle cleavages with the loss of the neutral acetylketene molecule and the formation of $\left[\mathrm{M}-\mathrm{H}_{2} \mathrm{O}\right]^{+}$ions as a result of the ortho-effect. $^{8}$ 

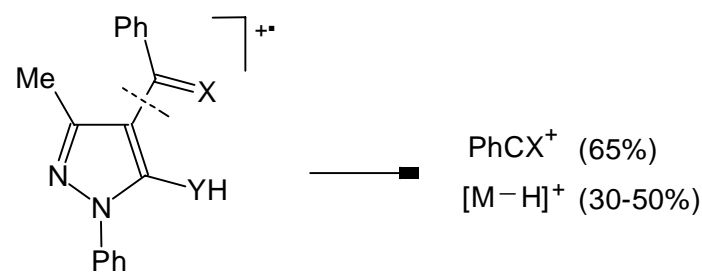
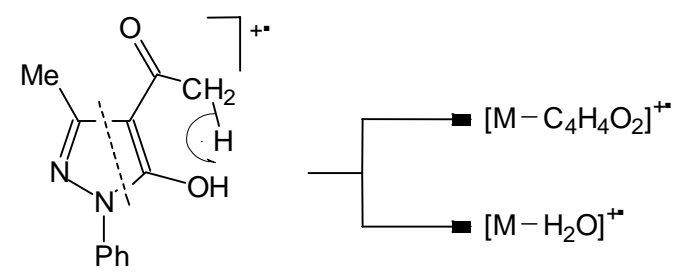

$X, Y=O, S$

Scheme 5. Mass-spectrometrical fragmentation of aromatic 1-phenylpyrazolines (Refs. [7, 8]).

The mass spectra of some typical compounds $\mathbf{4}$ and $\mathbf{5}$ are listed in Table 7. The evenelectron $[\mathrm{M}-\mathrm{H}]^{+}$cations in the spectra of $\mathbf{5}$ are considerably less intensive $(<5 \%$ rel. int.) than in the previously studied aromatic pyrazolones. ${ }^{7}$ All the compounds produce abundant acetyl cations. Noteworthy in the spectra of compounds $\mathbf{4}$ is the "retrosynthetic" cleavage of the hydrazide $\mathrm{C}-\mathrm{N}$ bond producing $\mathrm{C}_{4} \mathrm{H}_{5} \mathrm{O}_{2}{ }^{+}$cations (1-3\% of the total ion current, TIC) and the complementary $\left[\mathrm{M}-\mathrm{C}_{4} \mathrm{H}_{4} \mathrm{O}_{2}\right]^{+\bullet}$ ions ( $\mathbf{A}^{+\bullet}$, Table 8) which subsequently lose either a hydrogen atom or the $\mathrm{R}^{3}$ substituent. Fragmentation through the $\mathrm{N}-\mathrm{N}$ bond cleavage is less intensive. The aromatic ring substituents also affect the overall fragmentation. Thus, the nitro group in $\mathbf{4 h}$ both destabilizes the $\mathbf{M}^{+\bullet}$ ions and decreases the relative contribution of $\mathbf{A}^{+\bullet}$ ions (and their daughter ions) to the TIC as compared to other compounds (Table 8). Peaks of $\left(\mathbf{A}-\mathrm{R}^{3}\right)^{+}$ions are absent from the spectrum of $\mathbf{4 i}\left(\mathrm{R}^{3}=\mathrm{Ph}\right)$.

Table 7. The 70-eV EI mass spectra of selected compounds 4 and 5. Peaks of ions with $\mathrm{m} / \mathrm{z}>$ 40 and relative intensity $\geq 10 \%$ are listed

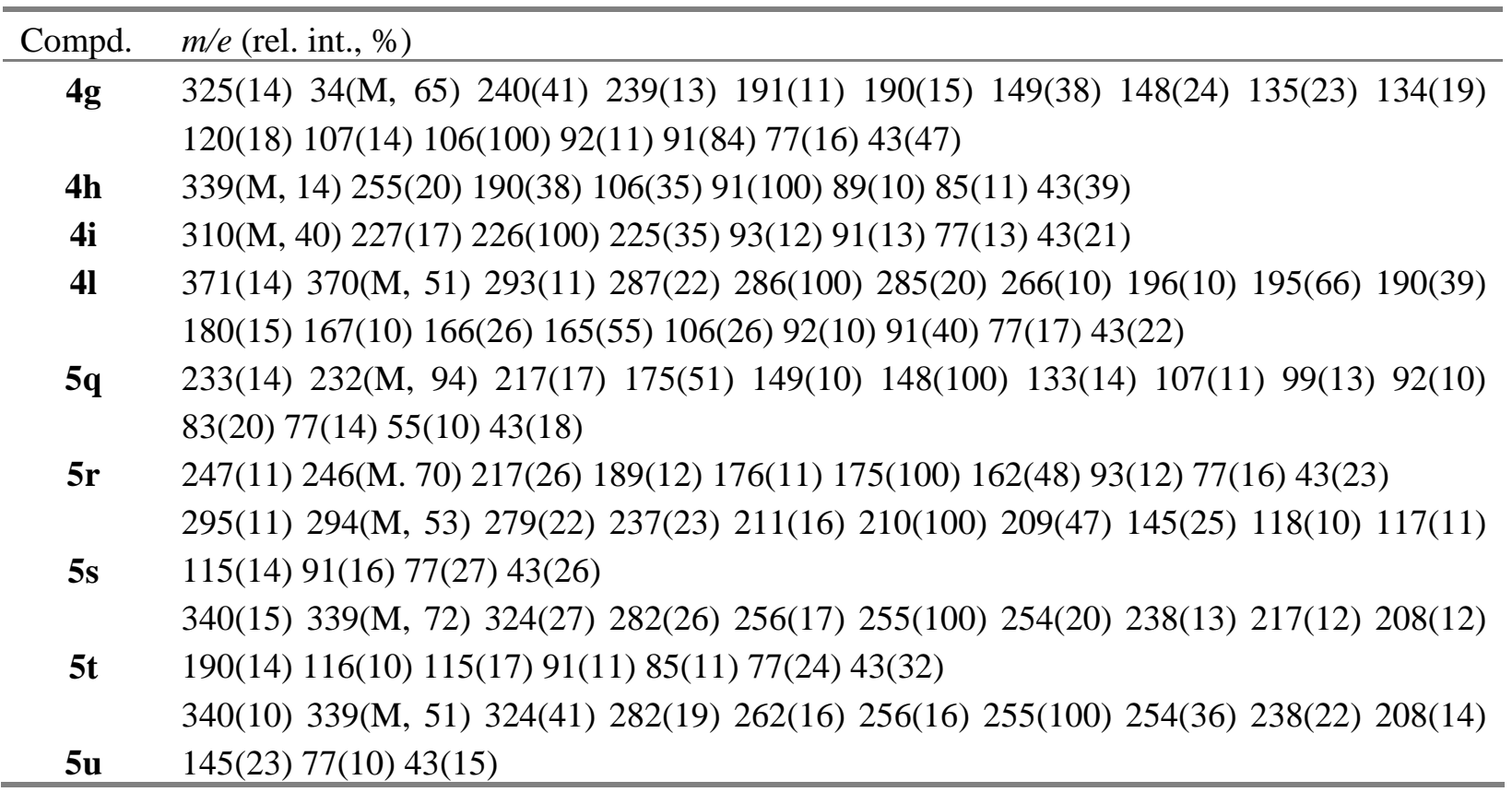


Some of the characteristic fragment ions for compounds $\mathbf{5 q - u}$ are listed in Table 9. The base peaks in all these spectra (except $5 \mathbf{r}$ ) correspond to $\left[\mathrm{M}-\mathrm{C}_{4} \mathrm{H}_{4} \mathrm{O}_{2}\right]^{+\bullet}$ ions $\left(\mathbf{B}^{+\bullet}\right)$ formed as a result of the pyrazolidine ring cleavage with the loss of neutral acetylketene. In spite of their identical composition, the $\left[\mathrm{M}-\mathrm{C}_{4} \mathrm{H}_{4} \mathrm{O}_{2}\right]^{+\bullet}$ ions formed from compounds $\mathbf{4}$ and $\mathbf{5}$ obviously differ in structure (hence the $\mathbf{A}$ and $\mathbf{B}$ notation). This is indicated by either low intensity or the total absence of $\left(\mathbf{B}-\mathrm{R}^{3}\right)$ daughter ions in contrast to $\left(\mathbf{A}-\mathrm{R}^{3}\right)$ ions. The subsequent fragmentation of $\left[\mathrm{M}-\mathrm{C}_{4} \mathrm{H}_{4} \mathrm{O}_{2}\right]^{+\bullet}$ via a hydrogen loss is more characteristic of 3-arylsubstituted compounds 5. Moreover, metastable transitions corresponding to the direct formation of [M $\left.\mathrm{C}_{4} \mathrm{H}_{5} \mathrm{O}_{2}\right]^{+}$from $\mathrm{M}^{+}$could not be detected. As a rule, substituents in position 3 are lost as neutral species, with the positive charge remaining in the heterocycle. In contrast, peaks of [M $\left.-\mathrm{CH}_{3} \mathrm{CO}\right]^{+}$ions have low intensity. Further fragmentation of $[\mathrm{M}-\mathrm{R}]^{+}$ions is accompanied by ketene loss, which leads to $\left[\mathrm{M}-\mathrm{C}_{3} \mathrm{H}_{5} \mathrm{O}\right]^{+}$ions in the case of $\mathrm{R}=\mathrm{Me}$.

Table 8. Abundances of characteristic ions (\% TIC) in the 70-eV EI mass spectra of selected N-acetoacetylhydrazones 4

\begin{tabular}{ccccccccc}
\hline Compound & $\mathbf{M}^{+\bullet}$ & $\begin{array}{c}{\left[\mathrm{M}-\mathrm{C}_{4} \mathrm{H}_{4} \mathrm{O}_{2}\right]^{+}} \\
=\mathrm{A}^{+\bullet}\end{array}$ & $\begin{array}{c}(\mathrm{A}- \\
\mathrm{H})^{+}\end{array}$ & $\begin{array}{c}(\mathrm{A}- \\
\left.\mathrm{R}_{3}\right)^{+}\end{array}$ & $\mathrm{R}^{1} \mathrm{R}^{2} \mathrm{CN}^{+}$ & $\mathrm{R}^{3} \mathrm{NCOCH}_{2} \mathrm{Ac}^{+}$ & $\mathrm{C}_{7} \mathrm{H}_{7}^{+}$ & $\mathrm{Ac}^{+}$ \\
\hline $\mathbf{4 g}$ & 10.5 & 5.3 & 1.7 & 4.9 & 2.5 & 1.9 & 10.9 & 6.1 \\
$\mathbf{4 h}$ & 4.1 & 4.7 & 0.6 & 1.4 & -- & 8.8 & 26.0 & 11.2 \\
$\mathbf{4 i}$ & 13.0 & 26.2 & 9.1 & -- & 1.3 & -- & -- & 5.5 \\
$\mathbf{4 l}$ & 9.0 & 13.5 & 2.7 & 8.9 & 2.0 & 5.3 & 5.4 & 2.9 \\
\hline
\end{tabular}

Table 9. Relative abundances of characteristic ions (\% TIC) in the 70-eV EI mass spectra of selected 4-acetyl-1-phenylpyrazoline-3-ones 5

\begin{tabular}{|c|c|c|c|c|c|c|c|c|c|}
\hline Compd. & $\mathrm{M}^{+\bullet}$ & $\begin{array}{c}{[\mathrm{M}-} \\
\left.\mathrm{R}^{1}\right]^{+}= \\
(\mathrm{M}- \\
\mathrm{Me})\end{array}$ & $\begin{array}{l}{[\mathrm{M}-} \\
\left.\mathrm{R}^{2}\right]^{+}\end{array}$ & $\begin{array}{c}{\left[\mathrm{M}-\mathrm{R}^{1}-\right.} \\
\left.\mathrm{CH}_{2} \mathrm{CO}\right]^{+}\end{array}$ & $\begin{array}{c}{\left[\mathrm{M}-\mathrm{R}^{2}-\right.} \\
\left.\mathrm{CH}_{2} \mathrm{CO}\right]^{+}\end{array}$ & $\begin{array}{c}{\left[\mathrm{M}-\mathrm{C}_{4} \mathrm{H}_{4} \mathrm{O}_{2}\right]^{+\bullet}} \\
=\mathrm{B}^{+\bullet}\end{array}$ & $\begin{array}{c}{\left[\mathrm{B}^{+\bullet}-\right.} \\
\mathrm{H}]^{+}\end{array}$ & $\mathrm{R}^{1} \mathrm{R}^{2} \mathrm{C}_{3} \mathrm{OH}^{+}$ & $\mathrm{Ac}^{+}$ \\
\hline $5 q$ & 18.4 & \multicolumn{2}{|c|}{2.9} & \multicolumn{2}{|c|}{8.6} & 16.8 & 1.0 & 3.4 & 3.1 \\
\hline $5 r$ & 12.6 & 0.5 & 4.0 & 1.9 & 15.5 & 7.5 & 0.3 & 1.5 & 3.6 \\
\hline $5 s$ & 10.2 & 3.6 & 1.5 & 3.7 & 0.9 & 16.1 & 7.6 & 4.0 & 4.2 \\
\hline $5 t$ & 12.2 & 3.8 & 1.6 & 3.6 & 1.2 & 13.9 & 2.7 & 2.0 & 4.4 \\
\hline $5 \mathbf{u}$ & 10.0 & 6.7 & 2.6 & 3.2 & 0.6 & 16.3 & 5.9 & 3.7 & 2.4 \\
\hline
\end{tabular}



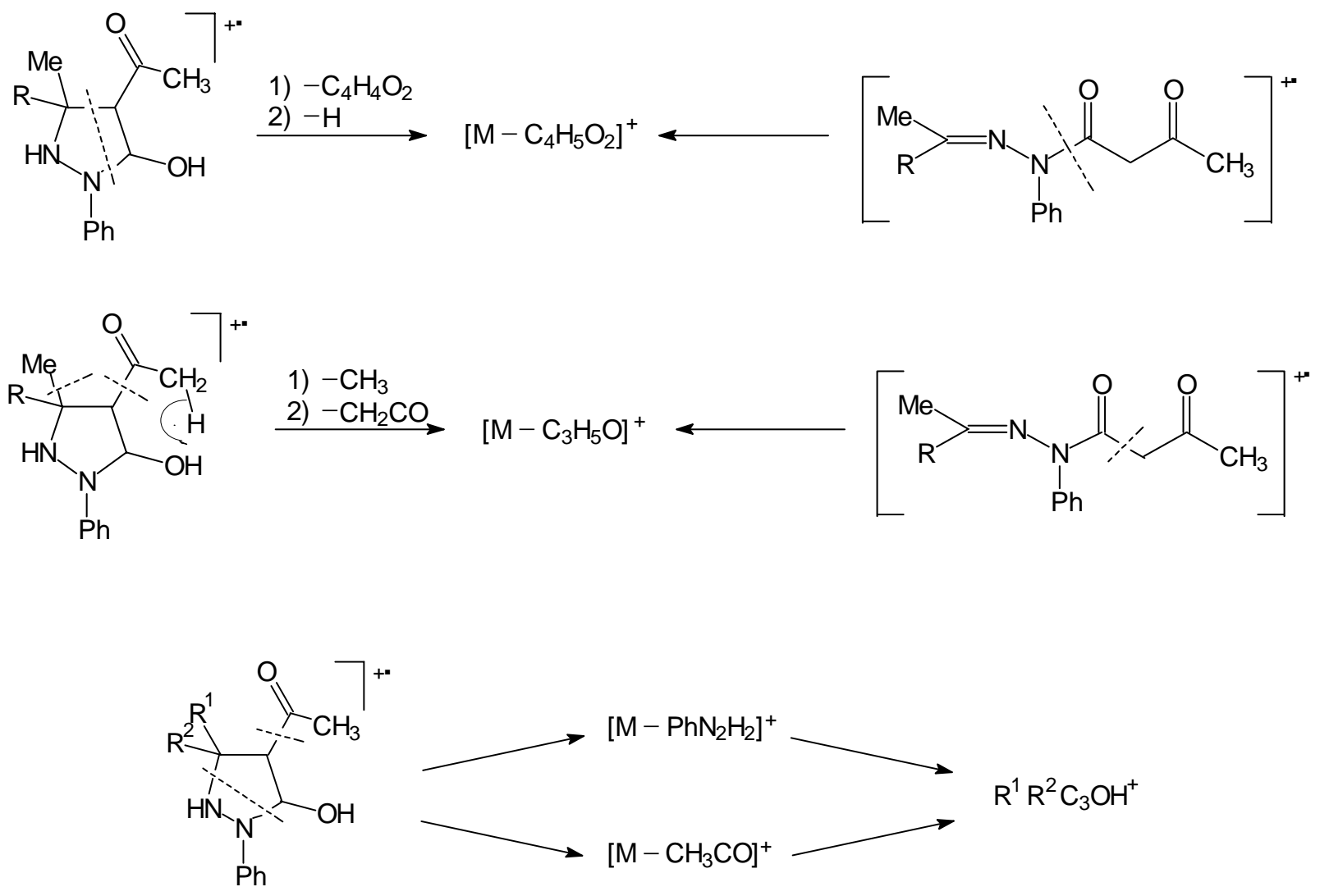

Scheme 6. Specific fragmentation paths of compounds 5q-u under EI.

Direct formation of $\left[\mathrm{M}-\mathrm{C}_{3} \mathrm{H}_{5} \mathrm{O}\right]^{+}$from $\mathrm{M}^{+\bullet}$, which might indicate the existence of $\mathrm{M}^{+\bullet}$ in the form of linear acetoacetylhydrazones (Scheme 6) was confirmed by metastable transitions only in two cases, $\mathbf{5 q}$ and $\mathbf{5 t}$. The relatively stable $\mathrm{R}^{1} \mathrm{R}^{2} \mathrm{C}_{3} \mathrm{OH}^{+}$ions (Scheme 6) are of special interest. They are always formed in two steps via two alternative routes. One is the loss of $\mathrm{PhN}_{2} \mathrm{H}$ from rather unstable $\left[\mathrm{M}-\mathrm{CH}_{3} \mathrm{CO}\right]^{+}$ions, and the other involves the loss of ketene from $\left[\mathrm{M}-\mathrm{PhN}_{2} \mathrm{H}_{2}\right]^{+}$ions. Both fragmentation routes are somewhat unexpected because the phenylhydrazine moiety is lost as a neutral particle, although the $\mathrm{PhN}_{2} \mathrm{CMe}^{+}$and $\mathrm{PhN}_{2}{ }^{+}$ions are known to be quite abundant in the mass spectrum of a closely related compound, 3-methyl-1phenylpyrazole-5-one. ${ }^{8}$ Most importantly, the formation of $\mathrm{R}^{1} \mathrm{R}^{2} \mathrm{C}_{3} \mathrm{OH}^{+}$ions is an irrefutable evidence for the cyclic structure of $\mathrm{M}^{+\bullet}$ of compounds $\mathbf{5}$ (Scheme 6). The clear differences in the mass-spectrometric fragmentation of compounds $\mathbf{4}$ and $\mathbf{5}$ under EI show that their molecular ions exist predominantly in the same form (linear acetoacetylhydrazones and pyrazolidinones, respectively) as the corresponding neutral compounds in the condensed phase. In other words, the ring-chain isomerisation does not take place in the gas phase. 
The dual course of the diketene reaction with hydrazones, namely, the formation of linear $\mathbf{4}$ and cyclic $\mathbf{5}$ products is especially noteworthy, since these compounds are structurally similar to a number of other functionally substituted hydrazones which are capable of ring-chain tautomerism. ${ }^{9}$ By analogy, this tautomerism could also be expected to take place in compounds 4 and 5. It stands to reason that promoting proton abstraction from the $\alpha$-position of the acetoacetyl group (in the linear derivatives 4) or from the nitrogen atom (in the cyclic derivatives 5) could facilitate the ring-chain transition. However, neither prolonged heating of typical representatives of compounds $\mathbf{4}$ and $\mathbf{5}$ in pyridine at $70^{\circ} \mathrm{C}$, nor their treatment with sodium methylate in alcohol with subsequent neutralization resulted in any isomerisation. Hence, acetoacetylhydrazones, similarly to the closely related cyanoacetylhydrazones, ${ }^{10}$ do not exhibit ring-chain tautomerism in solution.

The mass spectra of typical representatives of compounds $\mathbf{9}$ are listed in Tables 10 and 11 . The even-electron cations $[\mathrm{M}-\mathrm{H}]^{+}$are much less abundant ( $<5 \%$ of relative intensity) than in the spectra of aromatic pyrazolones. ${ }^{7}$ All the compounds produce abundant phenyl cations, and the presence of benzyl substituents (in 9d) is manifested by strong $\mathrm{C}_{7} \mathrm{H}_{7}{ }^{+}$peaks. The base peak in the spectrum of the sec-butylamine derivative 9c corresponds to $\mathrm{C}_{2} \mathrm{H}_{6} \mathrm{~N}^{+}$ions. The massspectrometric fragmentation of compounds 9 (Tables 10 and 11) involves the loss of substituents from position 3 and the heterocyclic ring cleavages at the N1-C5 and C3-C4 bonds. The positive charge is distributed between the resulting phenylhydrazone and enamine/enehydrazine fragments so that the $\mathrm{PhMeCN} \mathrm{N}_{2} \mathrm{HPh}\left(\mathrm{C}_{14} \mathrm{H}_{14} \mathrm{~N}_{2}{ }^{+\bullet}\right)$ ions are less abundant than the corresponding $\left[\mathrm{M}-\mathrm{C}_{14} \mathrm{H}_{13} \mathrm{~N}_{2}\right]^{+}$in all cases.

The formation of abundant $\mathrm{RNC}_{2} \mathrm{H}_{3}{ }^{+}$ions raises questions about the actual structure of the substituent in position 4, considering the possibility of double-bond migration. The $\mathrm{RNC}_{2} \mathrm{H}_{3}{ }^{+}$ ions could be formed from $\mathrm{M}^{+\bullet}$ simply by the $\mathrm{C}-\mathrm{C}$ bond cleavage if the molecular ion structures were closer to the 4-(1-iminoethyl) substituted (A) rather than aminoethylidenesubstituted (B) pyrazolidinone (Fig. 1 and Scheme 4). The observed metastable transitions confirmed that $\mathrm{RNC}_{2} \mathrm{H}_{3}{ }^{+}$are directly formed from either $\mathrm{M}^{+\bullet}$ or $[\mathrm{M}-\mathrm{Me}]^{+}$ions in one step. Since the NMR study demonstrated that compounds $\mathbf{9}$ predominantly exist in solution as the enamine isomers in which the substituent in position 4 is bound to the heterocycle by a $\mathrm{C}=\mathrm{C}$ double bond, it was interesting to compare the relative stabilities of possible valence isomers of $\mathrm{M}^{+\bullet}$ in order to establish the most probable precursor of $\mathrm{RNC}_{2} \mathrm{H}_{3}{ }^{+}$ions in the gas phase. Although quantum-chemical calculations at the semiempirical level are generally considered as not sophisticated enough to provide fine structural details, their use is justified in this particular case as we were only interested in a qualitative comparison of bond lengths in the $\mathrm{M}^{+\bullet}$ radical cations derived from different neutral precursor isomers.

Table 10. The 70-eV EI mass spectra of compounds 9 . Peaks of ions with $m / z>40$ and relative abundance $\geq 5 \%$ are listed

\begin{tabular}{lll}
\hline Compd. & m/e (\% RA) \\
\hline $\mathbf{9 b}$ & 308(8) 307(M, 37) 294(6) 293(23) 292(100) 261(7) 231(6) 230(37) 210(10) 209(7) 200(6) 199(5) \\
$\mathbf{9 e}$ & 158(11) 98(15) 77(11) 56(40) \\
\hline
\end{tabular}




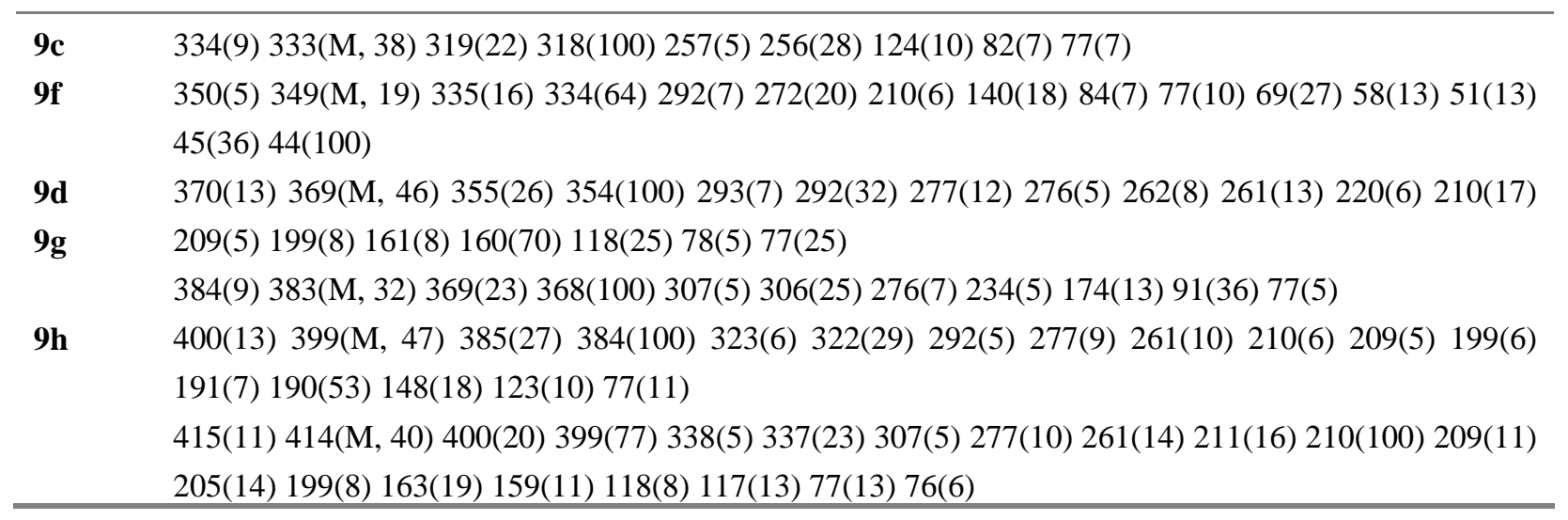

Table 11. Characteristic ions (\% of the total ion current) in the mass spectra of compounds 9

\begin{tabular}{cccccccc}
\hline Compd. & $\mathrm{M}^{+\bullet}$ & {$[\mathrm{M}-\mathrm{Me}]^{+}$} & {$[\mathrm{M}-\mathrm{Ph}]^{+}$} & {$\left[\mathrm{M}-\mathrm{C}_{14} \mathrm{H}_{13} \mathrm{~N}_{2}\right]^{+}$} & $\mathrm{C}_{14} \mathrm{H}_{14} \mathrm{~N}_{2}{ }^{+}$ & $\mathrm{C}_{14} \mathrm{H}_{13} \mathrm{~N}_{2}{ }^{+}$ & $\mathrm{RNC}_{2} \mathrm{H}_{3}^{+}$ \\
\hline $\mathbf{9 b}$ & 9.8 & 21.6 & 8.0 & 3.2 & 2.2 & 1.6 & 8.6 \\
$\mathbf{9 c}$ & 3.5 & 9.6 & 3.0 & 2.6 & 0.9 & 0.6 & $0.4^{\mathrm{a}}$ \\
$\mathbf{9 d}$ & 11.0 & 26.4 & 6.6 & 3.4 & 0.9 & 0.9 & $-^{\mathrm{b}}$ \\
$\mathbf{9 e}$ & 11.9 & 24.6 & 6.9 & 2.5 & 0.6 & 0.8 & 1.7 \\
$\mathbf{9 f}$ & 10.1 & 16.6 & 5.3 & 11.6 & 2.9 & 0.9 & 4.2 \\
$\mathbf{9 g}$ & 10.8 & 17.5 & 5.1 & 9.2 & 1.1 & 0.8 & 3.2 \\
$\mathbf{9 h}$ & 8.1 & 12.4 & 3.6 & 2.3 & 16.2 & 1.8 & 3.0 \\
\hline
\end{tabular}

${ }^{\mathrm{a}} \mathrm{C}_{2} \mathrm{H}_{6} \mathrm{~N}^{+} 15.0 \% . \mathrm{C}_{2} \mathrm{H}_{7} \mathrm{~N}^{+\bullet} 5.0 \% ;{ }^{\mathrm{b}} \mathrm{C}_{7} \mathrm{H}_{7}{ }^{+}$9.6\% (9d) ; ${ }^{\mathrm{C}} \mathrm{PhMeNN}{ }^{+}$

\section{Calculations}

The enthalpies of formation, charge distributions and bond parameters of various $\mathrm{M}^{+\bullet}$ isomers were calculated for the $\mathrm{N}$-methylated derivative $\mathbf{9 b}$ at the semiempirical level of MO theory (PM3/UHF approximation) using the MOPAC software. ${ }^{11}$

Fig. 1 shows the optimized geometries of $\mathrm{M}^{+\bullet}$ isomers which correspond to the iminoethyland aminoethylidene-substituted neutral molecules. Note that the calculated enthalpies of formation are only slightly different (by $<10 \mathrm{kcal} / \mathrm{mol}$ ) for the double-bond isomers of $\mathrm{M}^{+\bullet}$. Since the excess of internal energy obtained by a neutral molecule after electron impact exceeds both this value and any plausible energy of activation for the double-bond shift, the isomeric molecular ions $\mathrm{M}^{+\bullet}(\mathbf{A})$ and $\mathrm{M}^{+\bullet}$ (B) (Fig. 1) derived from the corresponding doublebond isomers (Scheme 4) are likely to co-exist in the gas phase regardless of the neutral precursor structure. Their fragmentation leads to the identical $\mathrm{MeCN}^{+} \mathrm{Me}$ ions, but the calculated enthalpies of formation of the accompanying $\mathrm{C}_{16} \mathrm{H}_{15} \mathrm{~N}_{2} \mathrm{O}^{\bullet}$ radicals are considerably different. The radical formed from $\mathrm{M}^{+\bullet}$ (A) is by $45 \mathrm{kcal} / \mathrm{mol}$ more stable than its counterpart, and these thermochemical considerations suggest that the formation of $\mathrm{RNC}_{2} \mathrm{H}_{3}{ }^{+}$from $\mathrm{M}^{+\bullet}$ (A) would be more advantageous than from $\mathrm{M}^{+\bullet}(\mathbf{B})$. 

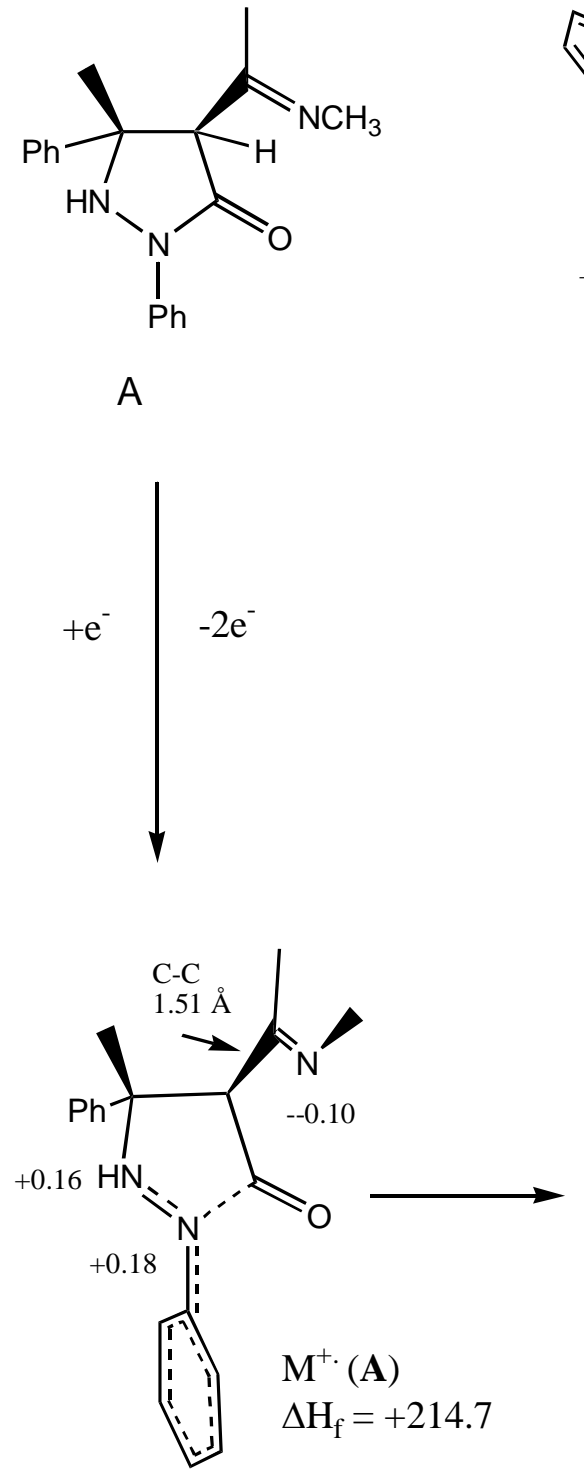

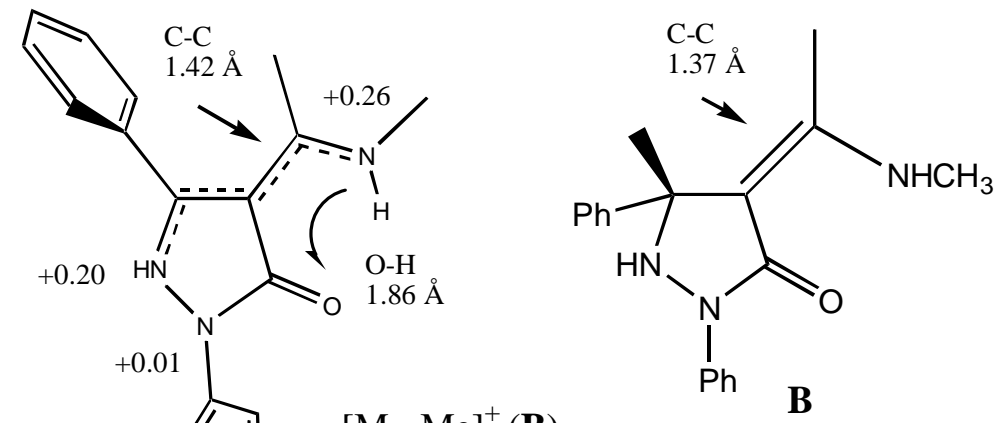

$[\mathrm{M}-\mathrm{Me}]^{+}(\mathbf{B})$

$\Delta \mathrm{H}_{\mathrm{f}}=+203.7$

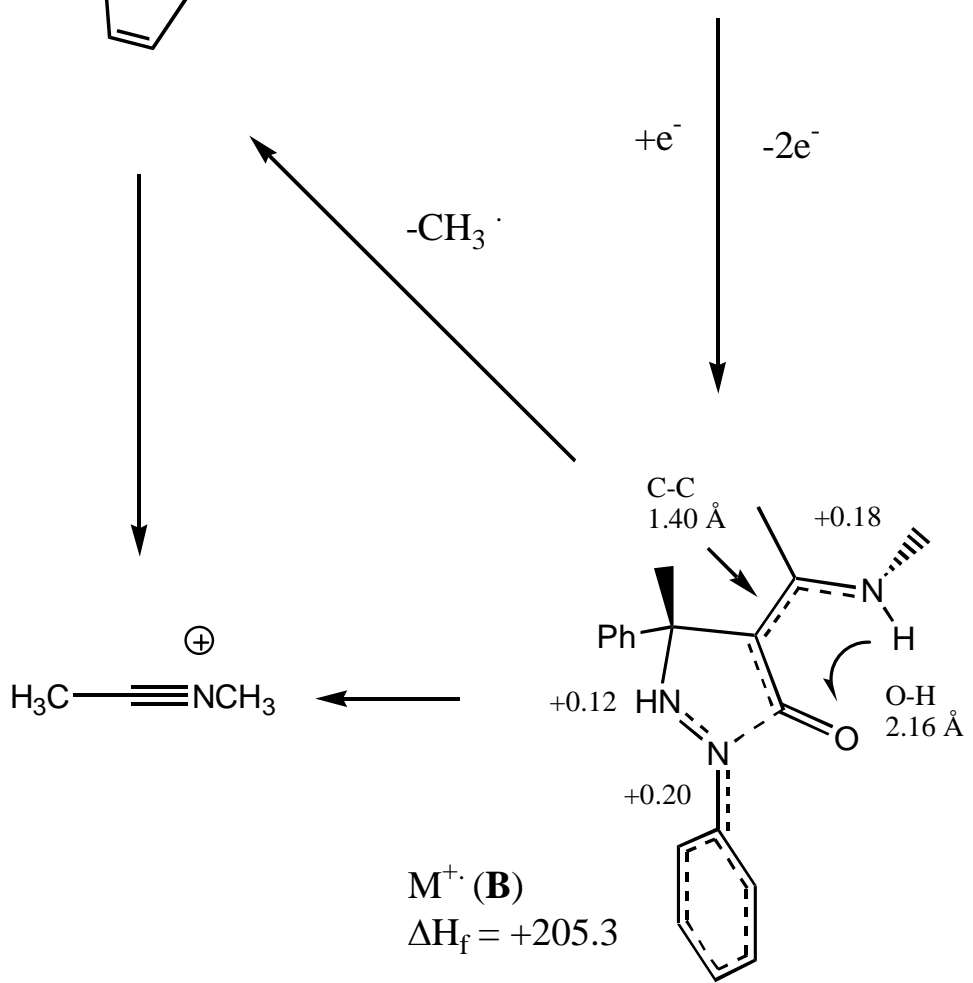

Figure 1. PM3/UHF optimized geometries of the hypothetical $\mathrm{M}^{+\bullet}$ and $\left[\mathrm{M}-\mathrm{CH}_{3}\right]^{+}$isomers for compound $\mathbf{9 b}$.

However, the optimized geometry of $\mathrm{M}^{+\bullet}$ (B) (Fig. 1) shows that the ionization of the neutral $\mathbf{B}$ causes considerable elongation of the $\mathrm{C}-\mathrm{C}$ bond between the heterocycle and the substituent in position 4 . The distribution of the positive charge in $\mathbf{M}^{+\bullet}(\mathbf{A})$ and $\mathrm{M}^{+\bullet}(\mathbf{B})$ differs considerably (Fig. 1), so that the nitrogen atom incorporated in the emerging $\mathrm{MeCN}^{+} \mathrm{Me}$ ion bears a positive partial charge only in the $\mathrm{M}^{+\bullet}(\mathbf{B})$ and $\left[\mathrm{M}-\mathrm{CH}_{3}\right]^{+}(\mathbf{B})$ structures but not in the $\mathrm{M}^{+\bullet}$ (A) structure. Thus, in principle the $\mathrm{RNC}_{2} \mathrm{H}_{3}{ }^{+}$ions can be formed directly from the $\mathrm{M}^{+\bullet}(\mathbf{B})$ and $\left[\mathrm{M}-\mathrm{CH}_{3}\right]^{+}(\mathbf{B})$ ions corresponding to the enamine isomer $\mathbf{B}$ of compounds $\mathbf{9}$ which predominate in solution. This process would involve a hydrogen transfer to the carbonyl oxygen as shown in Fig. 1. 


\section{Conclusions}

The reaction of diketene with N-alkyl- and N-arylhydrazones of ketones is shown to be (with a few exceptions) a universal method for synthesizing 2,5,5-trisubstituted 4-acetylpyrazolidin-3ones, whereas the reaction with $\mathrm{N}$-alkyl- and $\mathrm{N}$-arylhydrazones of aldehydes leads to openchain $\mathrm{N}$-acetoacetyl-N-alkyl(aryl)hydrazones.

Similarly to the parent compounds (2,5,5-trisubstituted 4-acetylpyrazolidin-3-ones), imines 9 do not appear to form linear isomers either in solution or in the gas phase. Thus, ring-chain tautomerism involving activated $\mathrm{C}-\mathrm{H}$ bonds still remains elusive.

\section{Experimental Section}

General Procedures. ${ }^{1} \mathrm{H}$ and ${ }^{13} \mathrm{C}$ NMR spectra were recorded on Bruker DPX 300 spectrometer at a resonance frequency of $300.130 \mathrm{MHz}$ for ${ }^{1} \mathrm{H}$ and at $75.47 \mathrm{MHz}$ for ${ }^{13} \mathrm{C}$ or on JEOL JNM-L-400 at a resonance frequency of $399.78 \mathrm{MHz}$ for ${ }^{1} \mathrm{H}$ and $100.54 \mathrm{MHz}$ for ${ }^{13} \mathrm{C}$. Chemical shifts $(\delta)$ are expressed in ppm against $\mathrm{Me}_{4} \mathrm{Si}$ as internal standard, coupling constants $(J)$ are given in $\mathrm{Hz}$. Spectra were recorded at $25^{\circ} \mathrm{C}$ using solvent $\mathrm{CDCl}_{3}$ or DMSO- $d_{6}$, solution concentrations were $5-15 \%$. The delay time in the NOESY experiments was $1 \mathrm{~s}$.

The EI mass spectra (ionization energy $70 \mathrm{eV}$, ion source temperature $160^{\circ} \mathrm{C}$, direct insertion) were recorded on a VG ZabSpec instrument (VG Analytical, Manchester, UK). Fragmentation paths were confirmed by metastable ions spectra $\left(B / E\right.$ and $B^{2} / E$ linked scans, decompositions observed in the 1FFR). Elemental compositions of fragment ions were determined at a resolving power of $8000-10000$ (at 10\% valley definition) by peak matching technique using PFK as a reference compound.

The molecular ion structures for compound $\mathbf{3 b}$ were optimized using the PM3 basis, unrestricted Hartree-Fock (UHF) method, and the EF (eigenvector following) routine for geometry optimization included in the MOPAC 6.0 program. ${ }^{11}$ Only ground electronic states were considered.

Synthesis. The starting hydrazones 2 were obtained by the known method. ${ }^{12}$ Oximes 6 were obtained as commercial products and additionally purified by sublimation at a reduced pressure. Compounds $\mathbf{4 i}$, 5q-u were obtained by methods reported in the literature. ${ }^{2}$ The physicochemical properties and elemental analyses of the synthesized compounds are listed in Table 12.

Table 12. Physicochemical characteristics and analytical data for the studied compounds

\begin{tabular}{|c|c|c|c|c|c|}
\hline Compound & $\mathrm{Mp},{ }^{\circ} \mathrm{C}$ & Formula & Eler & & $\mathrm{R}_{\mathrm{f}}$ \\
\hline & & & Calculated & Found & \\
\hline
\end{tabular}




\begin{tabular}{|c|c|c|c|c|c|c|c|c|c|c|}
\hline & & & & $\mathrm{C}$ & $\mathrm{H}$ & $\mathrm{N}$ & $\mathrm{C}$ & $\mathrm{H}$ & $\mathrm{N}$ & \\
\hline \multirow[t]{2}{*}{3} & $\mathbf{a}$ & $127-129$ & $\mathrm{C}_{10} \mathrm{H}_{18} \mathrm{~N}_{4} \mathrm{O}$ & 57.12 & 8.63 & 26.64 & 58.14 & 8.66 & 26.55 & $0.65^{\mathrm{a}}$ \\
\hline & $\mathbf{b}$ & $148-150$ & $\mathrm{C}_{20} \mathrm{H}_{22} \mathrm{~N}_{4} \mathrm{O}$ & 71.83 & 6.63 & 16.75 & 71.75 & 6.68 & 16.72 & $0.42^{\mathrm{a}}$ \\
\hline \multirow[t]{10}{*}{4} & c & Oil & $\mathrm{C}_{8} \mathrm{H}_{14} \mathrm{~N}_{2} \mathrm{O}_{2}$ & 56.45 & 8.29 & 16.46 & 56.37 & 8.32 & 16.39 & $0.60^{\mathrm{b}}$ \\
\hline & d & Oil & $\mathrm{C}_{12} \mathrm{H}_{14} \mathrm{~N}_{2} \mathrm{O}_{2}$ & 66.04 & 6.47 & 12.84 & 65.97 & 6.50 & 12.79 & $0.73^{b}$ \\
\hline & $\mathbf{e}$ & Oil & $\mathrm{C}_{15} \mathrm{H}_{20} \mathrm{~N}_{2} \mathrm{O}_{2}$ & 69.20 & 7.74 & 10.76 & 69.26 & 7.82 & 10.78 & $0.75^{\mathrm{b}}$ \\
\hline & $\mathbf{f}$ & $73-75$ & $\mathrm{C}_{18} \mathrm{H}_{18} \mathrm{~N}_{2} \mathrm{O}_{2}$ & 73.45 & 6.16 & 9.52 & 73.44 & 6.09 & 9.51 & $0.41^{b}$ \\
\hline & g & $108-110$ & $\mathrm{C}_{19} \mathrm{H}_{20} \mathrm{~N}_{2} \mathrm{O}_{3}$ & 70.15 & 6.21 & 8.64 & 70.18 & 6.22 & 8.64 & $0.50^{\mathrm{b}}$ \\
\hline & $\mathbf{h}$ & $175-177$ & $\mathrm{C}_{18} \mathrm{H}_{17} \mathrm{~N}_{3} \mathrm{O}_{4}$ & 63.71 & 5.05 & 12.38 & 63.73 & 5.03 & 12.42 & $0.52^{\mathrm{c}}$ \\
\hline & $\mathbf{i}$ & $109-111$ & $\mathrm{C}_{18} \mathrm{H}_{18} \mathrm{~N}_{2} \mathrm{O}_{3}$ & 69.66 & 5.85 & 9.03 & 69.61 & 5.87 & 9.05 & $0.4^{\mathrm{b}}$ \\
\hline & $\mathbf{j}$ & Oil & $\mathrm{C}_{11} \mathrm{H}_{20} \mathrm{~N}_{2} \mathrm{O}_{2}$ & 62.23 & 9.50 & 13.20 & 62.26 & 9.57 & 13.17 & $0.46^{\mathrm{c}}$ \\
\hline & $\mathbf{k}$ & Oil & $\mathrm{C}_{17} \mathrm{H}_{24} \mathrm{~N}_{2} \mathrm{O}_{2}$ & 70.80 & 8.39 & 9.71 & 70.75 & 8.42 & 9.76 & $0.64^{b}$ \\
\hline & 1 & $117-119$ & $\mathrm{C}_{24} \mathrm{H}_{22} \mathrm{~N}_{2} \mathrm{O}_{2}$ & 77.81 & 5.99 & 7.56 & 77.79 & 6.04 & 7.60 & $0.76^{\mathrm{b}}$ \\
\hline \multirow[t]{9}{*}{5} & $\mathbf{m}$ & Oil & $\mathrm{C}_{13} \mathrm{H}_{16} \mathrm{~N}_{2} \mathrm{O}_{2}$ & 67.22 & 6.94 & 12.06 & 67.27 & 6.89 & 12.12 & $0.45^{\mathrm{c}}$ \\
\hline & $\mathbf{n}$ & Oil & $\mathrm{C}_{10} \mathrm{H}_{18} \mathrm{~N}_{2} \mathrm{O}_{2}$ & 60.58 & 9.15 & 14.13 & 61.52 & 9.18 & 14.22 & $0.67^{\mathrm{b}}$ \\
\hline & $\mathbf{0}$ & $126-128$ & $\mathrm{C}_{15} \mathrm{H}_{20} \mathrm{~N}_{2} \mathrm{O}_{2}$ & 69.20 & 7.74 & 10.76 & 69.19 & 7.74 & 10.71 & $0.62^{b}$ \\
\hline & $\mathbf{p}$ & Oil & $\mathrm{C}_{14} \mathrm{H}_{18} \mathrm{~N}_{2} \mathrm{O}_{2}$ & 68.27 & 7.37 & 11.37 & 68.25 & 7.40 & 11.33 & $0.70^{\mathrm{c}}$ \\
\hline & $\mathbf{q}$ & $111-113$ & $\mathrm{C}_{13} \mathrm{H}_{16} \mathrm{~N}_{2} \mathrm{O}_{2}$ & 67.22 & 6.94 & 12.06 & 67.26 & 6.89 & 12.09 & $0.52^{\mathrm{b}}$ \\
\hline & $\mathbf{r}$ & $79-81$ & $\mathrm{C}_{14} \mathrm{H}_{18} \mathrm{~N}_{2} \mathrm{O}_{2}$ & 68.27 & 7.37 & 11.37 & 68.23 & 7.35 & 11.37 & $0.48^{\mathrm{b}}$ \\
\hline & $\mathbf{s}$ & $114-115$ & $\mathrm{C}_{18} \mathrm{H}_{18} \mathrm{~N}_{2} \mathrm{O}_{2}$ & 73.45 & 6.16 & 9.52 & 73.49 & 6.21 & 9.47 & $0.69^{b}$ \\
\hline & $\mathbf{t}$ & $99-101$ & $\mathrm{C}_{18} \mathrm{H}_{17} \mathrm{~N}_{3} \mathrm{O}_{4}$ & 63.71 & 5.05 & 12.38 & 63.78 & 5.02 & 12.42 & $0.55^{\mathrm{c}}$ \\
\hline & $\mathbf{u}$ & $163-165$ & $\mathrm{C}_{18} \mathrm{H}_{17} \mathrm{~N}_{3} \mathrm{O}_{4}$ & 63.71 & 5.05 & 12.38 & 62.70 & 5.06 & 12.36 & $0.42^{\mathrm{c}}$ \\
\hline \multirow[t]{3}{*}{7} & $\mathbf{a}$ & Bp 96-98 (1 mmHg) & $\mathrm{C}_{6} \mathrm{H}_{9} \mathrm{NO}_{3}$ & 50.35 & 6.34 & 9.79 & 50.41 & 6.29 & 9.77 & $0.67^{\mathrm{c}}$ \\
\hline & $\mathbf{b}$ & Oil & $\mathrm{C}_{7} \mathrm{H}_{11} \mathrm{NO}_{3}$ & 53.49 & 7.05 & 8.91 & 53.54 & 7.11 & 8.85 & $0.75^{d}$ \\
\hline & c & Oil & $\mathrm{C}_{12} \mathrm{H}_{13} \mathrm{NO}_{3}$ & 65.74 & 5.98 & 6.39 & 65.84 & 6.07 & 6.35 & $0.56^{\mathrm{d}}$ \\
\hline \multirow[t]{8}{*}{9} & $\mathbf{a}$ & Oil & $\mathrm{C}_{11} \mathrm{H}_{21} \mathrm{~N}_{3} \mathrm{O}$ & 62.52 & 10.02 & 19.89 & 62.57 & 10.08 & 19.85 & $0.41^{\mathrm{c}}$ \\
\hline & $\mathbf{b}$ & $150-152$ & $\mathrm{C}_{19} \mathrm{H}_{21} \mathrm{~N}_{3} \mathrm{O}$ & 74.24 & 6.89 & 13.67 & 74.19 & 6.83 & 13.57 & $0.64^{\mathrm{a}}$ \\
\hline & c & $101-103$ & $\mathrm{C}_{22} \mathrm{H}_{27} \mathrm{~N}_{3} \mathrm{O}$ & 75.61 & 7.79 & 12.02 & 75.67 & 7.70 & 11.97 & $0.58^{\mathrm{a}}$ \\
\hline & d & $141-143$ & $\mathrm{C}_{25} \mathrm{H}_{25} \mathrm{~N}_{3} \mathrm{O}$ & 78.30 & 6.57 & 10.96 & 78.41 & 6.62 & 10.89 & $0.75^{\mathrm{b}}$ \\
\hline & $\mathbf{e}$ & $98-100$ & $\mathrm{C}_{21} \mathrm{H}_{23} \mathrm{~N}_{3} \mathrm{O}$ & 75.65 & 6.95 & 12.60 & 75.59 & 6.95 & 12.65 & $0.59^{b}$ \\
\hline & $\mathbf{f}$ & $172-174$ & $\mathrm{C}_{24} \mathrm{H}_{23} \mathrm{~N}_{3} \mathrm{O}$ & 78.02 & 6.27 & 11.37 & 78.11 & 6.17 & 11.39 & $0.46^{\mathrm{b}}$ \\
\hline & g & $165-167$ & $\mathrm{C}_{25} \mathrm{H}_{25} \mathrm{~N}_{3} \mathrm{O}_{2}$ & 75.16 & 6.31 & 10.52 & 75.17 & 6.28 & 10.56 & $0.70^{\mathrm{c}}$ \\
\hline & $\mathbf{h}$ & 183-185 & $\mathrm{C}_{24} \mathrm{H}_{22} \mathrm{~N}_{4} \mathrm{O}_{3}$ & 69.55 & 5.35 & 13.52 & 69.58 & 5.37 & 13.54 & $0.62^{\mathrm{c}}$ \\
\hline
\end{tabular}

${ }^{\mathrm{a}}$ benzene-acetonitrile $5: 1$; ${ }^{\mathrm{b}}$ benzene-acetonitrile $2: 1$; ${ }^{\mathrm{c}}$ benzene-acetonitrile $1: 1$; ${ }^{\mathrm{d}}$ chloroformmethanol 10:1.

Preparation of hydrazono azines (3a, b). To a stirred solution of $16 \mathrm{mM}$ hydrazone 2 in chloroform at $-23^{\circ} \mathrm{C}\left(\mathrm{CCl}_{4} /\right.$ dry ice) $8 \mathrm{mM}$ of diketene was added with stirring in $15 \mathrm{~min}$. The reaction mixture was kept in a refrigerator overnight. The precipitate was recrystallized from a chloroform-hexane mixture. Yields 70-80\%.

Preparation of $\mathrm{N}$-substituted $\mathrm{N}$-acetoacetylhydrazones (4c-h, j-l) and 2,5,5-trisubstituted 4-acetylpyrazolidine-3-ones (5m-p). To a stirred solution of $10 \mathrm{mM}$ of hydrazone 2 in 
absolute benzene at $0^{\circ} \mathrm{C}, 11 \mathrm{mM}$ of diketene was added with stirring for $15 \mathrm{~min}$ in the presence of catalytic amounts of glacial acetic acid. The mixture was allowed to react for $1 \mathrm{~h}$, then the solvent was removed under vacuum. The residue was purified on a column packed with silica gel (5-40 $\mu$, eluent: benzene-acetonitrile $5: 1)$. Crystalline products were purified by recrystallization from a chloroform-hexane mixture. Yields 40-60\%.

Preparation of O-acetoacetyloximes (7a-c). To a stirred solution of $10 \mathrm{mM}$ of oxime 6 in absolute ether at $0^{\circ} \mathrm{C}, 11 \mathrm{mM}$ of diketene was added with stirring for $15 \mathrm{~min}$. The mixture was allowed to react for $30 \mathrm{~min}$, then the solvent was removed under vacuum. The residue was purified on a column packed with silica gel (5-40 $\mu$, eluent: benzene-acetonitrile 5:1). Yields 50-60\%. Compound $7 \mathbf{b}$ was purified by vacuum distillation.

Preparation of methyl imines of 4-acetyl-2-isopropyl-5-methyl-5-phenylpyrazolidin-3-one (9a) and 4-acetyl-2,5-diphenyl-5-methylpyrazolidin-3-one (9b). Stream of methylamine was bubbled through a stirred solution of the corresponding hydrazone $4 \mathbf{e}$ or pyrazolidinone 5 s (10 mmol) in absolute benzene. After the reaction was completed (monitored by TLC), the solvent was removed under reduced pressure. The residue was recrystallised from a chloroform-hexane mixture. Yields 85-90\%.

Preparation of imines of 2,5,5-trisubstituted 4-acetyl-pyrazolidin-3-ones (9c-h). Amine 8 (10 mmol) was added with stirring to a solution of the corresponding pyrazolidinone $5 \mathbf{s}$ (10 mmol) in absolute benzene in the presence of catalytic amounts of acetic acid. The solvent was removed under reduced pressure. The residue was recrystallised from a chloroform-hexane mixture. Yields 70-90\%.

\section{Acknowledgements}

The authors wish to thank the Academy of Finland for financial support.

\section{References}

1. Clemens, R. J. Chem. Rev. 1986, 86, 241.

2. Kato, T.; Katagiri, N. Chem. Pharm. Bull. 1970, 18, 2269.

3. Oleinik, S. V.; Zelenin, K. N.; Alekseyev, V. V.; Potekhin, A. A. Khim. Geterotsikl. Soed. 1999, 35, 748.

4. Kato, T.; Katagiri, N. Chem. Pharm. Bull. 1970, 18, 2278.

5. (a) Walter, W; Reubke, K. -J. Chem. Ber. 1970, 103, 2197. (b) Stewart, W. E.; Siddall,T. H. Chem. Rev. 1970, 70, 517.

6. Zelenin, K. N.; Yakimovich, S. I. Zh. Obshch. Khim. 1983, 65, 705.

7. Herzschuh, R.; Hinsche, G.; Uhlemann, E. Z. Z. Chem. 1983, 23, 411.

8. Wilde, H.; Herzschuh, R.; Lepom, P; Mann, G. J. prakt. Chem. 1981, 323, 14.

9. Zelenin, K. N.; Alekseyev, V. V. Khim. Geterotsikl. Soed. 1988, 1, 1. 
10. Zelenin, K. N.; Oleinik, S. V.; Alekseyev, V. V.; Potekhin, A. A. Zh. Obshch. Khim. 2001, $71,1182$.

11. Stewart J. J. P., MOPAC 6.0, QCPE No. 455, Indiana Univ., Bloomington, IN, 1990.

12. Kost, A. N.; Sagitullin, R. S. Zh. Obshch. Khim. 1963, 33, 367. 